\title{
Potential uses of G-quadruplex-forming aptamers *
}

\author{
Viktor Viglasky ${ }^{1 *}$ and Tibor Hianik ${ }^{2 *}$ \\ ${ }^{1}$ Department of Biochemistry, Institute of Chemistry, Faculty of Sciences, P. J. Šafárik University, Košice, Slovak Republic \\ ${ }^{2}$ Department of Nuclear Physics and Biophysics, Faculty of Mathematics, Physics and Informatics, Comenius University, \\ Bratislava, Slovak Republic
}

\begin{abstract}
Guanine quadruplex (G-quadruplex) structures are one of a number of structures which are capable of adopting aptamers. G-rich DNA or RNA has an increased propensity to form quadruplex structures which have unusual biophysical and biological properties. G-rich aptamers which form G-quadruplexes have several advantages over unstructured sequences: G-quadruplexes are non-immunogenic, thermodynamically and chemically stable and they have both higher resistance to various serum nucleases and an enhanced cellular uptake. These advantages have led to a number of synthetic oligonucleotides being studied for their potential use as therapeutic agents for cancer therapy and in the treatment of various other diseases. In addition to their suitability in the fields of medicine and biotechnology, these, highly specified, aptameric G-quadruplexes also have great potential in the further development of nano-devices; e.g. basic components in microarrays, microfluidics, sandwich assays and electrochemical biosensors. This review summarizes the biophysical properties of G-quadruplexes and highlights the importance of the stability and recognition properties of aptamers. Examples of the application of aptamers in medical therapy and in biosensors are also discussed.
\end{abstract}

Key words: DNA aptamers - G-quadruplex - Circular dichroism - Biosensors

\begin{abstract}
Abbreviations: CD, circular dichroism; DCR, double-chain reversal loop; DSC, differential scanning calorimetry; EW, edge-wise loop; Fc, ferocene; FET, field effect transistors, IRMPD, infrared multiphoton dissociation; LOD, limit of detection; ISFET, ion-sensitive FET; MB, methylene blue; NMR, nuclear magnetic resonance; PQQGDH, pyrroquinoleine quinine glucose dehydrogenase; PSMA, proteins such as nucleolin prostate-specific membrane antigen; QCM, quartz crystal microbalance; SELEX, systematic evolution of ligands by exponential enrichment; SLE, systemic lupus erythemathosus; SPR, surface plasmon resonance; TBA, thrombin binding aptamer; VEGF, vascular endothelial growth factor.
\end{abstract}

\section{Introduction}

DNA and RNA aptamers are single stranded oligonucleotides which, under certain conditions, fold into 3D structures containing specific binding sites for low or macro

Correspondence to: Viktor Viglasky, Department of Biochemistry, Institute of Chemistry, Faculty of Sciences, P. J. Šafárik University, Moyzesova 11, 04001 Košice, Slovak Republic

E-mail: viktor.viglasky@upjs.sk

Tibor Hianik, Department of Nuclear Physics and Biophysics, Faculty of Mathematics, Physics and Informatics, Comenius University, 84248 Bratislava, Slovak Republic

E-mail: Tibor.Hianik@fmph.uniba.sk molecular compounds of various types, including cells, cell surface proteins, bacteria and viruses. Their specificity is comparable to and, in certain cases, even higher than those of antibodies. In contrast to antibodies, aptamers are prepared by an in vitro selection procedure developed independently in the early 1990s by three separate groups of investigators. Robertson and Joyce (1990) have described the method of RNA selection with improved enzymatic activity to cleave DNA. Tuerk and Gold (1990) patented

\footnotetext{
\# Both authors contributed equally to this work.

* This article was presented at the $5^{\text {th }}$ Slovak Biophysical Symposium, organised by The Slovak Biophysical Society in Bratislava, March 19-21, 2012
} 
the process of the selection of DNA ligands as a target for T4 RNA polymerase. This method is known as SELEX (systematic evolution of ligands by exponential enrichment). Ellington and Szostak (1990) reported a method of in vitro selection of RNA which binds specifically to organic dyes. This paper also introduced the term "aptamer" (from the Latin aptus, meaning "to fit" and Greek meros, meaning "the part"). The identification of aptamers is based on a combinatorial approach. Specific oligonucleotides are isolated from complex libraries of synthetic nucleic acids. For this purpose, random sequence DNA libraries are obtained by automated DNA synthesis. The size of a randomized region can vary from 30 to 60 nucleotides, flanked on both sides with a specific, unique DNA sequence for polymerase chain

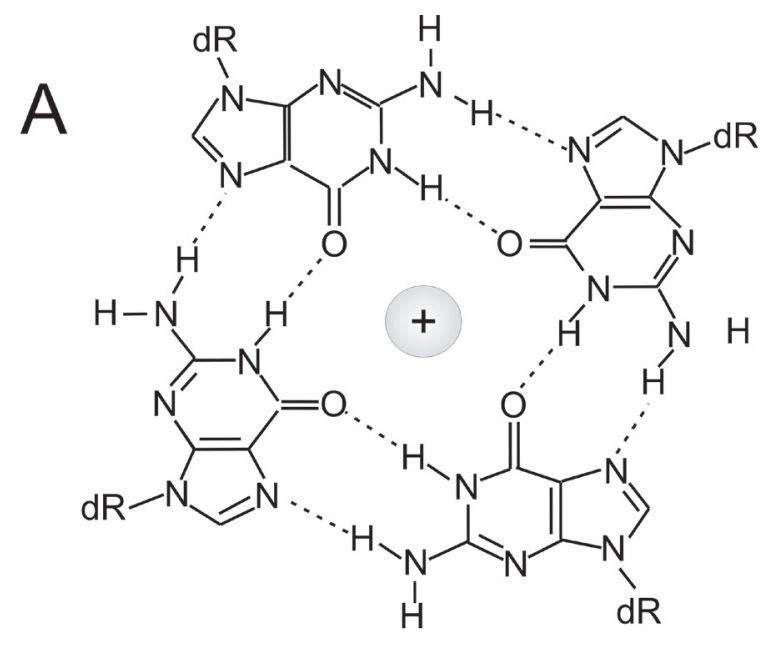

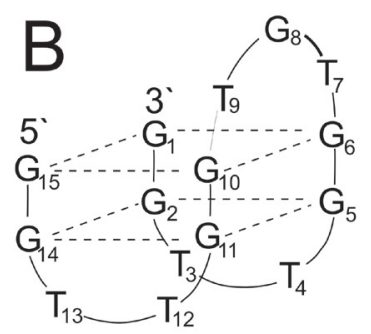

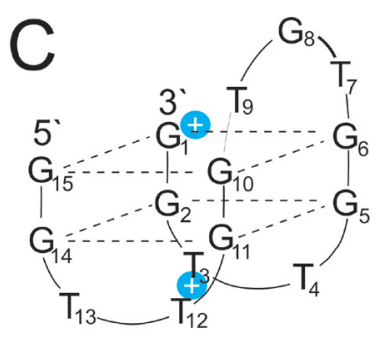

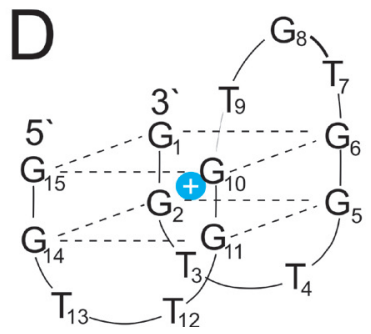

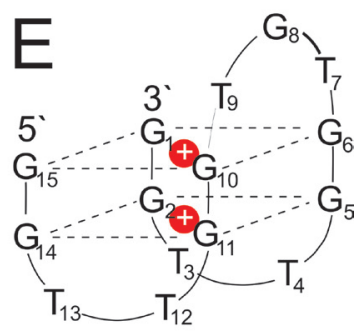

Figure 1. A. Scheme of G-quartet structure. B. G-quadruplex of thrombin binding aptamers (TBA). Possible localization of $\mathrm{K}^{+}(\mathbf{C}$, D) and $\mathrm{Na}^{+}(\mathbf{E})$ ions in TBA. reaction (PCR) amplification. The theoretical diversity of individual oligonucleotides in these random DNA libraries is relatively wide; for example, $4^{40}=1.2 \times 10^{24}$ in the case of oligonucleotides composed of 40 bases. In practice, however, a considerably smaller library of approximately $10^{13}-10^{15}$ molecules is used (Jayasena 1999). The selection consists of DNA binding with immobilized ligands, such as proteins or other compounds. The stability of complexes is characterized by the apparent dissociation constant, $\mathrm{K}_{\mathrm{D}}$. For aptamer-protein complexes, $\mathrm{K}_{\mathrm{D}}$ usually varies within the $1-100 \mathrm{nM}$ range, which is similar to that of antibody-antigen complexes. However, some aptamers bind to target protein with $\mathrm{pM}$ order of $\mathrm{K}_{\mathrm{D}}$ value, e.g. $\mathrm{K}_{\mathrm{D}}$ of PDGF-B DNA aptamer is 100 pM (Green et al. 1996) and $\mathrm{K}_{\mathrm{D}}$ of VEGF RNA aptamer is $49 \mathrm{pM}$ (Ruckman et al. 1998). Unbound DNA/RNA molecules are eluted from the column, while bound aptamers are isolated from the complex and then amplified by PCR. This cycle is repeated several times (around 6 to 10) and as a result the DNA or RNA sequence with a high affinity to the target ligand is obtained. The SELEX technique has been discussed in detail in a number of papers and reviews (see, for example Keefe and Cload 2008; Strehlitz and Stoltenburg 2009).

Initially the aptamers were based on RNA and were selected against bacteriophage T4 DNA polymerase (Tuerk and Gold 1990) or fluorescent dyes (Elington and Szostak 1990). However, then Bock et al. (1992) selected a DNA aptamer specific to human a thrombin (TBA). TBA is a 15 -mer guanine rich aptamer of the sequence d(GGTTGGTGTGGTTGG) which selectively binds to the fibrinogen binding site of thrombin. This binding site is responsible for the cleavage of the fibrinogen which results in the formation of fibrin clots in blood. In fact the work by Bock et al. (1992) was the first successful practical application of aptamers. The binding of TBA to thrombin inhibits the cleavage of fibrinogen and thus protects its coagulative function and prevents the formation of thrombus. TBA derivative named Nu172 has recently undergone the first phase of clinical trials (Becker at al. 2010). This aptamer is currently being evaluated in Phase II of the clinical trials for anticoagulation in heart disease treatments by ARCA Biopharma (Ni et al. 2011).

NMR studies have revealed that TBA in the presence of $\mathrm{K}^{+}$ions folds into guanine quadruplexes (G-quadruplex) composed of two guanine tetrads connected by one TGT and two TT loops. Each tetrad is stabilized by Hoogsteen bonds (Fig. 1) (Wang et al. 1993; Adrian et al. 2012).

G-quadruplexes have been found also in other DNA aptamers (Table 1), although some aptamers do not contain these structures, for example aptamers sensitive to cellular prions (Ogasawara et al. 2009). The importance of G-quadruplexes lies in the stability of their 3D aptamer structure and in the improvement of electrostatic interactions to the positively 
Table 1. Examples of DNA aptamers contained G-quadruplexes

\begin{tabular}{|c|c|c|}
\hline Target/name & Sequence of Aptamer $\left(5^{\prime} \rightarrow 3^{\prime}\right)$ & References \\
\hline \multicolumn{3}{|l|}{ Protein targeted DNA aptamers } \\
\hline $\begin{array}{l}\text { Thrombin (TBA), sensitive to fibrinogen } \\
\text { binding site }\end{array}$ & GGTTGGTGTGGTTGG & $\begin{array}{l}\text { Bock et al. 1992; Padmanabhan et al. } \\
1993\end{array}$ \\
\hline Thrombin, sensitive to heparin binding site & GGTAGGGCAGGTTGG* $^{*}$ & Tasset et al. 1997 \\
\hline HIV integrase 93del & GGGGTGGGAGGAGGGT & $\begin{array}{l}\text { Jing and Hogan 1998; Jing et al. 2000; } \\
\text { De Soultrait et al. 2002; Phan et al. 2005; } \\
\text { Chou et al. } 2005\end{array}$ \\
\hline HIV-1 reverse transcriptase & $\begin{array}{l}\text { GGGGGTGGGAGGGTAGGCCTTAGG } \\
\text { TTTCTGA }\end{array}$ & Andreola et al. 2001 \\
\hline HIV-1 reverse transcriptase & $\begin{array}{l}\text { CGCCTGATTAGCGATACTCAGCGTT } \\
\text { GGGGGGGGGGGG }\end{array}$ & Michalowski et al. 2008 \\
\hline HIV-1 nucleocapsid protein & GGTTGGTGTGGTTGG & Kankia et al. 2005 \\
\hline $\begin{array}{l}\text { Anti HIV activity } \\
\text { Unknown specific target T30177 }\end{array}$ & GTGGTGGGTGGGTGGGT & Mukundan et. al. 2011 \\
\hline $\begin{array}{l}\text { Anti HIV activity } \\
\text { Unknown specific target T30695, T40214, } \\
\text { J19 }\end{array}$ & $\begin{array}{l}\text { GGGTGGGGTGGGTGGGT } \\
\text { GGGCGGGCGGGCGGGC } \\
\text { GIGTGGGTGGGTGGGT } \\
\end{array}$ & Do et al. 2011 \\
\hline HIV-1 gp120 V3 loop & TTGGGTT & Wyatt et al. 1994 \\
\hline HIV-1 gp120 V3 loop/CD4 binding site & TGGGAG & $\begin{array}{l}\text { Hotoda et al. 1998; Olieviero et al. 2010; } \\
\text { D`Antri et al. } 2012\end{array}$ \\
\hline VEGF Vap7 & $\begin{array}{l}\text { GCACTCTGTGGGGGTGGACGGGCC } \\
\text { GGGT }\end{array}$ & Nonaka et al. 2010 \\
\hline Nucleoin AS1411 & GGTGGTGGTGGTTGTGGTGGTGGTGG & Reyes-Reyes et al. 2010 \\
\hline $\begin{array}{l}\text { Signal transducer and activator of transcrip- } \\
\text { tion STAT3 }\end{array}$ & GGGCGGGCGGGCGGGC & Zhu and Jing 2007 \\
\hline Human RNase H1 & $\begin{array}{l}\text { CGGTCGCTCCGTGTGGCTTGGGTTG } \\
\text { GGTGTGGCAGTGAC }\end{array}$ & Pileur et al. 2003 \\
\hline Protein tyrosine phosphatase Shp2 & $\begin{array}{l}\text { AGCGTCGAATACCACACGGGGGTTT } \\
\text { TGGTGGGGGGGGCTGGGTTGTCTTG } \\
\text { GGGGTGGGCTAATGGAGCTCGTGGT } \\
\text { CAT }\end{array}$ & Hu et al. 2011 \\
\hline $\begin{array}{l}\text { Hepatitis C virus HCV RNA dependent } \\
\text { RNA polymerase }\end{array}$ & $\begin{array}{l}\text { GGGCGTGGTGGGTGGGGTACTAAT } \\
\text { AATGTGCGTTTG }\end{array}$ & Jones et al. 2006 \\
\hline SARS - CoV helicase & $\begin{array}{l}\text { AGCGGGCATATGGTGGTGGGTGGT } \\
\text { ATGGTC }\end{array}$ & Shum and Tanner 2008 \\
\hline M. tuberculosis polyphosphate kinase 2 & $\begin{array}{l}\text { AACACATAGGTTTGGTTAGGTTGGT } \\
\text { TGGTTGAATTA }\end{array}$ & Shum et al. 2011a \\
\hline Sclerostin & $\begin{array}{l}\text { TTGCGCGTTAATTGGGGGGGTGGGT } \\
\text { GGGTT }\end{array}$ & Shum et al. 2011b \\
\hline Insulin & $\begin{array}{l}\text { GGTGGTGGGGGGGGTTGGTAGGGT } \\
\text { GTCTTC }\end{array}$ & Yoshida et al. 2009 \\
\hline Tumor necrosis factor (TNF) VR11 & GGTGGATGGCGCAGTCGG & Orava et al. 2013 \\
\hline \multicolumn{3}{|l|}{ Non-protein targeted DNA aptamers } \\
\hline Ochratoxin A & $\begin{array}{l}\text { GATCGGGTGTGGGTGGCGTAAAGG } \\
\text { GAGCATCGGACA }\end{array}$ & Cruz-Aguado and Penner 2008 \\
\hline Hematoporphyrin IX & ATGGGGTCGGGCGGGCCGGGTGTC & Li et al. 1996; Okazawa et al. 2000 \\
\hline Hemin & GTGGGTAGGGCGGGTTGG & Travascio et al. 1998 \\
\hline Potassium ions & GGGTTAGGGTTAGGGTAGGG & Ueyama et al. 2002 \\
\hline ATP & CCTGGGGGAGTATTGCGGAGGAAGG & Huizenga and Szostak 1995 \\
\hline
\end{tabular}

* Flanked sequence stabilizing G-quadruplex of heparin/binding aptamers is not shown. 
charged binding side at the ligands. This is largely due to the fact that the negative charge density of G-quadruplexes is twice as high as that of linear DNA (Gatto et al. 2009), although other forces, such as Van der Waals, $\pi-\pi$ stacking and hydrophobic interactions are also important. The stability of the G-quadruplex is crucial in providing a high affinity of aptamers to the ligands. G-quadruplexes have been found also in RNA (Bugaut and Balasubramanian 2012).

The discovery of G-quadruplexes long predates that of DNA and RNA aptamers. In 1910 Bang published his observations of gel formations developing in high concentrations of guanylic acid in aqueous solutions (Bang 1910). Many years later, X-ray diffraction methods were used to determine that this gel was the result of the formation of guanine tetrameric units, so-called G-quartets (Gellert et al. 1962). G-quartet is formed by four guanines and is of planar square shape, and each guanine is both a donor and an acceptor of two hydrogen bonds (Fig. 1A). Several Gquartets then form $\mathrm{G}$-quadruplexes which are stabilized by $\pi-\pi$ interactions and, typically, the presence of $\mathrm{K}^{+}$or $\mathrm{Na}^{+}$ ions. G-quadruplexes became the subject of considerable interest after the discovery that the ends of human chromosomes - the telomeres - are composed of tandem repeats of guanine rich sequences d(TTAGGG) (Moyzis et al. 1988; Wang and Patel 1993). Studies using NMR revealed that these sequences fold into G-quadruplexes in vitro (Wang et al. 1993), and further work suggested that these structures are crucial in chromosome elongation by telomerase (Zahler et al. 1991). Further studies focused on the potential anti-cancer implications of G-quadruplexes; the overexpression of telomerase in cancer cells was targeted by blocking enzyme binding to G-quadruplexes using low molecular compounds which bind to quadruplexes (see MondragonSanchez et al. 2011; Bugaut and Balasubramanian 2012 and references herein). The discovery of end-telomere binding proteins suggests that G-quadruplexes are formed in vivo (Paeschke et al. 2005).

Recent years have also seen an increased interest in the use of aptamers in the development of drugs for treatment of various diseases. The RNA aptamer Macugen is one example of the successful application of aptamers in the treatment of neovascular age-related macular degeneration (Gragoudas et al. 2004). This aptamer was approved for clinical use in 2004. Other examples are DNA aptamers for treatment of HIV (Wyatt et al. 1994) and short guanine rich DNA aptamers which could potentially be used in the treatment of Huntington's disease (HD) connected with neuronal tissue degeneration (Skogen et al. 2006).

Aptamers have also attracted attention as potential biosensors which could replace more expensive and less stable antibodies (Hianik and Wang 2009; Lv et al. 2012; Tucker et al. 2012), in addition to acting as receptors for targeted drug delivery. In this second case, polymeric nanoparticles can be modified by aptamers specific to cancer markers which increase the affectivity of drugs which can be transported exclusively to the cancer cells (Farokhzad et al. 2004; Lee et al. 2011). Aptamers are also structurally flexible and simple molecular engineering can produce aptamer dimers which, similar to antibodies, contain two binding sites (Hianik et al. 2008; Ponikova et al. 2011).

In this review, we summarize recent developments in biophysical studies of the structural polymorphism and stability of guanine quadruplexes in DNA aptamers and in their application as receptors in biosensors, medical therapy and in drug delivery.

\section{Structural polymorphism of guanine quadruplexes and their physical properties}

G-quadruplexes can be formed by one, two or four single stranded oligonucleotides, known also as monomers, dimers and tetramers respectively. Interlocked G-quadruplexes can also consist of an odd number of oligomers, e.g. three, five, etc. Monomers and dimers have been further classified based on the loop regions into chair (lateral loop) or basket (diagonal loop). The relative oligonucleotide orientation $\left(5^{\prime}\right.$ to 3' polarity) can be parallel or antiparallel (Fig. 2) (Dapic et al. 2003). Circular dichroism (CD) is one of the most efficient methods for the identification of the polymorphism of G-quadruplexes (Gray et al. 2008; Viglasky et al. 2011).

CD spectra of G-quadruplexes are significantly different in comparison to the single-strand, duplex and other structural motifs of nucleic acids. A significant positive peak at $265 \mathrm{~nm}$ is the main feature for parallel strand arrangements, with positive peak at $295 \mathrm{~nm}$ being typical for antiparallel strand arrangements (Fig. 2H). However, we should exercise caution in data interpretation because the CD spectra tends to reflect the conformation of glycosidic bonds of guanines, anti, and syn configurations in G-tetrads rather than the entire strand orientation (Figs. 2A-G) (Masiero et al. 2010; Virgilio et al. 2012). Nonetheless, in most cases in which unmodified sequences are used, CD spectroscopy allows for discrimination between topological conformers of G-quadruplexes on the basis of strand orientation. For example, the overall G-quadruplex is composed of three stacked G-tetrads, and all tetrad guanines adopt anti conformation in parallel-stranded folding topology for many G-rich sequence repeats in $\mathrm{K}^{+}$e.g. promoter sequences $c-M y c$, HIV aptamers, the four-repeat human telomeric d[AGGG(TTAGGG) 3 ] sequence, the two-repeat human telomeric d[TAGGGTTAGGGT] sequence (Mukundan et al. 2011; Tong et al. 2011; Trajkovski et al. 2012). But once again, it is not a general rule that parallel G-quadruplexes are composed only of anti guanines; for example a RET promoter sequence forms a parallel structure in which one 
G-tetrad consists of four syn guanines (Tong et al. 2011). The CD signal of a molecule in which syn guanines also occur shows a slight positive peak at $295 \mathrm{~nm}$. This peak increases and appears to be more dominant with an increasing ratio of syn/anti for each G-quadruplex. A typical antiparallel structure reaches the ratio of 1.0; e.g. thrombin binding aptamer d[GGTTGGTGTGGTTGG], and human telomeric repeat d[AGGG(TTAGGG) 3 ] in $\mathrm{Na}^{+}$(Macaya et al. 1993; Lim et al. 2009; Russo Krauss et al. 2011). In this conformer clear positive and negative peaks to be observed at $295 \mathrm{~nm}$ and $240 \mathrm{~nm}$ respectively. In the case of the socalled hybrid structure of the promoter $\mathrm{Bcl}-2$ sequence and human telomeric sequence, in which one DCR (doublechain reversal) and two EW (edge-wise) loops are present, the ratio reaches value $5 / 7$ and both positive peaks at 295 and $265 \mathrm{~nm}$ are observed with CD. Recent studies have described G-quadruplex structures in which all three types of loops are present; EW, DCR and diagonal (Fig. 2E, Marusic et. al. 2012). In cases when more than one topological state is present in a solution, any signals will consist of all of the contributing states; similarly, the result of CD signal represents a mean value derived from all the contributing conformers dissolved in the solution.

Studies using differential scanning calorimetry (DSC) (Kankia and Marky 2001; Ponikova et al. 2011) and CD spectroscopy have shown that G-quadruplexes undergo significant temperature phase transitions; indeed, the amplitude of the selected peak in CD spectra is measured as a function of temperature. For antiparallel G-quadruplexes, a peak at $295 \mathrm{~nm}$ is typically selected (Kankia and Marky 2001; Fialová et al. 2006; Ponikova et al. 2008). This transition can be considered as a two-state transition for antiparallel G-quadruplexes, i.e. unfolded and folded, an expectation which was confirmed by DSC studies in which a clear maximum in heat capacity as a function of temperature was observed at transition temperature (approx. $50^{\circ} \mathrm{C}$ for TBA aptamers at presence of $50 \mathrm{mM} \mathrm{KCl}$, (Kankia and Marky 2001)), CD studies which demonstrated a sigmoidal shape of the amplitude of the elipticity at $295 \mathrm{~nm}$. This amplitude decreased with increasing temperature confirming that this band disappears in the unfolded state of the quadruplex. However, when different structures of the same sequence are present, the melting profile may differ from the sigmoidal. Recent studies have shown that the melting of the human telomeric sequence is not a two-state process and is characterized by several semi-transitions (Chaires 2010; Viglasky et al. 2010).

Research by Mergny et al. (1998) used a relatively simple method based on UV-spectroscopy to investigate the thermodynamic properties of some aptamers containing G-quadruplexes, and found that the absorbance of single stranded oligonucleotides containing G-quadruplexes has a positive signal at $295 \mathrm{~nm}$ and decreases with increasing temperature. When the plot of absorbance against temperature shows a sigmoidal shape, an analysis of the thermodynamic properties of the quadruplexes becomes possible. The shape of this dependence is similar to the plot of ellipticity
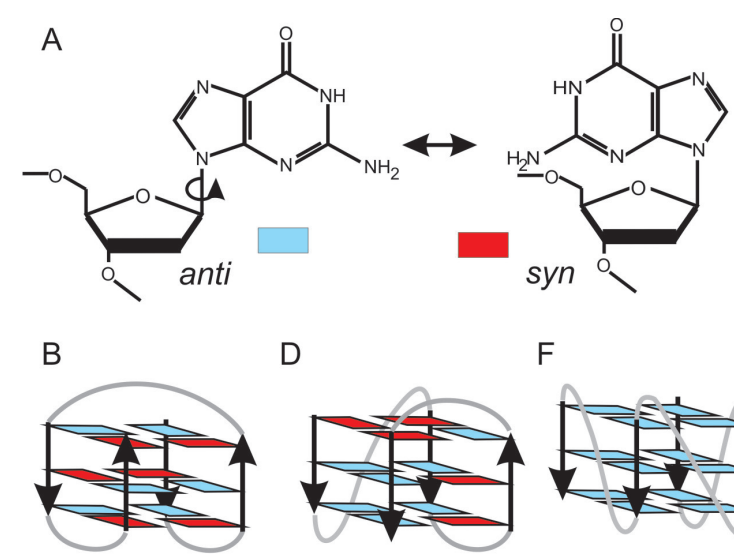

$\mathrm{D}$

F
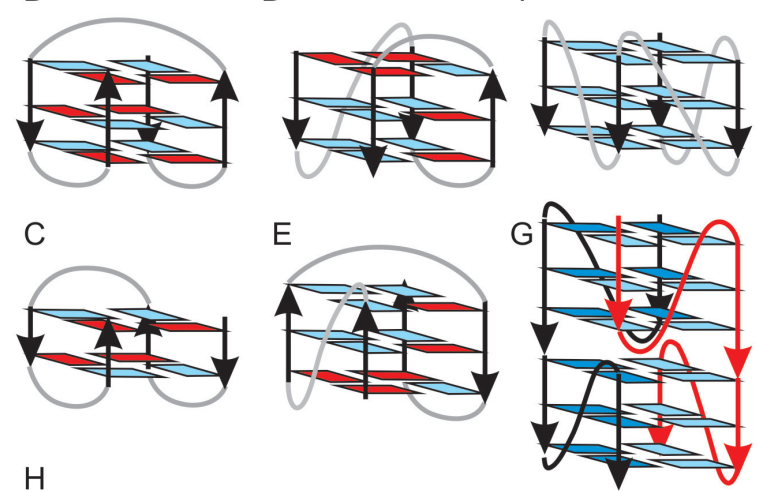

$\mathrm{H}$

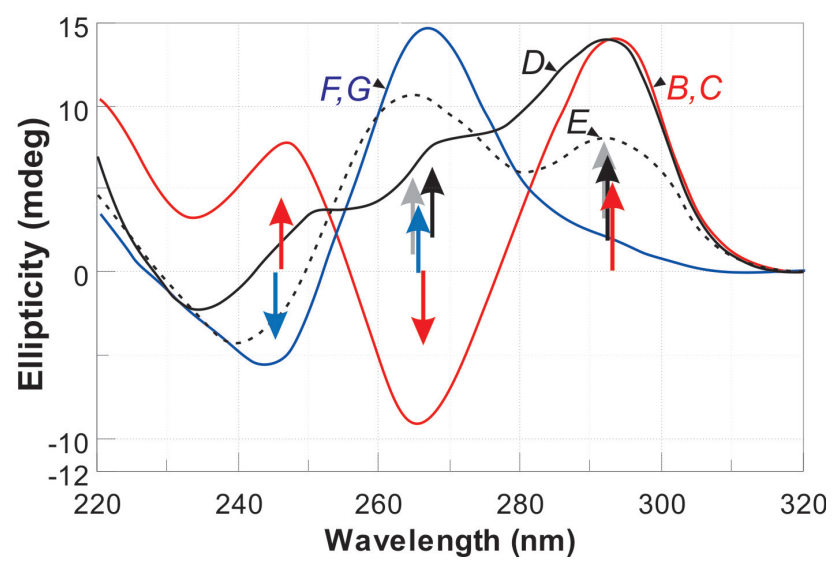

Figure 2. A. Syn and anti conformations of the guanine base relative to the sugar in nucleotides. B-F. Known G-quadruplex conformers that could be adopted by various aptamers consisting of G-rich DNA; basket (B), chair (C), hybrid-2 (D), hybrid-1 (E) and propeller structures containing double/triple quartet forms $(\mathbf{F}, \mathbf{G})$. The arrows indicate the parallel or anti-parallel orientation of DNA strands. Guanosine residues are colored according to the configuration of the glycosidic bond; anti and syn guanosines are colored aqua and red, respectively. A single DNA strand can fold upon itself to form an intramolecular G-quadruplex, while two DNA strands can assemble into a dimeric arrangement. G. Schematic representation of parallel interlocked conformers. $\mathrm{H}$. CD spectra that correspond to various G-quadruplex conformers depicted in panels A-F. 
at $292 \mathrm{~nm}$ against temperature obtained in CD experiments (Ponikova et al. 2008). In contrast, the absorbance at wavelength $\sim 260 \mathrm{~nm}$ rose with increasing temperature for intramolecular G-quadruplexes, althought the results suggesting G-quadruplex melting at this short wavelength is disputed and may result from inaccuracies in measurements (Mergny et al. 1998). Wallimann et al. (2003) were the first researchers to apply a dual-wavelength parametric test to verify a two-state melting mechanism for protein systems; improvements to this method resulted in the more advanced singular value decomposition method which was recently applied to the study of G-quadruplex melting mechanisms (Haq et al. 1997; Gray and Chaires 2011).

The analysis of the melting curves governed by a two-state mechanism yielded results which allowed the determination of phase transition temperature, $T_{m}$, and van't Hoff enthalpy changes $\left(\Delta H_{v H}\right)$ using a two-state approximation (Marky and Breslauer 1987). The melting curves can be extrapolated using the following equation:

$$
A=\frac{A_{F}+A_{U} e^{\left(\Delta H_{v H} / R\right) *\left(1 / T-1 / T_{m}\right)}}{1+e^{\left(\Delta H_{v H} / R\right) *\left(1 / T-1 / T_{m}\right)}}
$$

where $A$ is normalized absorbance, $A_{F}$ and $A_{U}$ are normalized absorbances of folded and unfolded states respectively. This approach has been used in the study of the thermodynamic properties of G-quadruplexes (mostly TBA) both in the presence of mono and divalent cations (Mergny et al. 1998; Kankia and Marky 2001) and also when nucleotides were substituted in the quadruplex loop (Ohsen et al. 2009). The loop part of the G-quadruplex has a considerable influ-

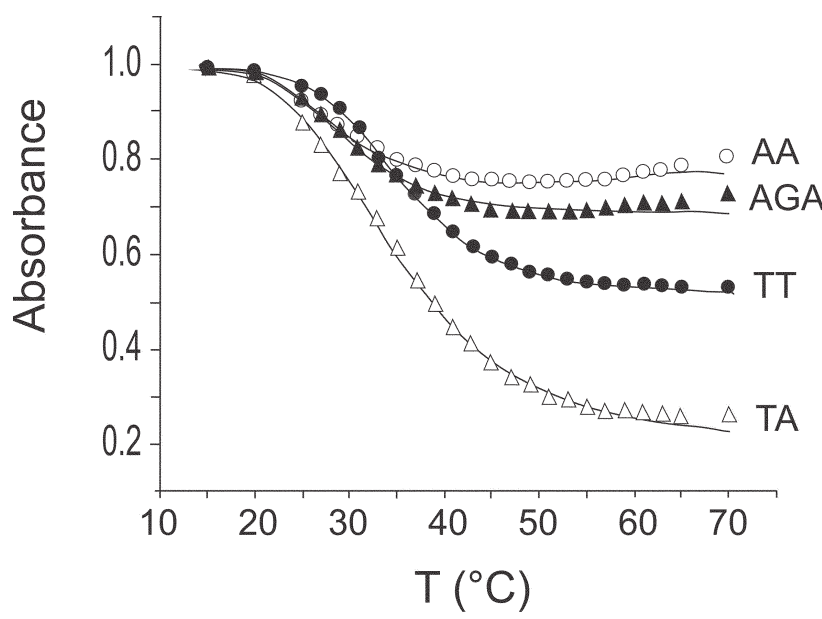

Figure 3. Normalized plot of absorbance at wavelength $297 \mathrm{~nm} v s$. temperature for all aptamers studied (see legend). The full lines are fits according to Eq. (1) (according to Lamberti et al. (2011) with permission of Springer). ence on the stability and binding properties of aptamers, and several studies have focused on the stability and binding properties of TBA aptamers depending on the substitution of nucleotides in two lateral TT and central TGT loops (see Tucker et al. 2012 and references herein). The modification of TGT loops have a substantial effect on the stability and binding properties of TBA aptamers; although substitution in $\mathrm{T}_{3}$ and $\mathrm{T}_{4}$ had little effect on TBA properties, the effect on $\mathrm{T}_{12}$ and $\mathrm{T}_{13}$ was remarkable (Coppola et al. 2008) (see Fig. 1B for TBA structure). Ohsen et al. (2009) studied the thermodynamic properties of TBA aptamers and showed that the substitution of nucleotides in TT loops by $\mathrm{U}$ and substitution of $\mathrm{G}$ in TGT loops by A, C or T increased the stability of the G-quadruplex. UV-spectroscopy was used to study the effect of the substitution of thymines by adenines in $\mathrm{T}_{3} \mathrm{~T}_{4}$ and TGT loops of the G-quadruplex on the thermodynamics and binding properties of aptamers (Lamberti et al. 2011). The following aptamers were used TT: 5'- GGT TGG TGT GGT TGG T 15 - 3'; AT: 5'- GGT TGG TGT GGA TGG T 15 - 3'; AA: 5'- GGT TGG TGT GGA AGG T15 - 3'; AGA: 5'- GGT TGG AGA GGT TGG T 15 - 3'. All aptamers were extended by 15 -mer thymine chains modified by biotin at the 3'-end in order to immobilize the aptamers on a solid support, and avidin-biotin technology was used to study the affinity interaction on the surfaces. The TT is a conventional TBA aptamer which is sensitive to fibrinogen binding site at thrombin. The other aptamers (AT, AA and AGA) differ from the TT aptamer through the substitution of thymines by adenines in the position marked with underlined bold in the description above. The plot of absorbance against temperature for all studied aptamers is presented in Fig. 3. It can be seen that the absorbance has the sigmoid shape which is typical in a two-state transition. The results obtained in the experiment can be input to Eq. (1) to determine of thermodynamics values of the aptamers (Table 2).

Table 2 shows that the substitution of nucleotides resulted in a decrease of $T_{m}$, and that the Gibbs energy changes

Table 2. The thermodynamics parameters of studied aptamers

\begin{tabular}{lcccc}
\hline Aptamer & $\begin{array}{c}T_{m} \\
\left({ }^{\circ} \mathrm{C}\right)\end{array}$ & $\begin{array}{c}\Delta H_{V H} \\
(\mathrm{~kJ} / \mathrm{mol})\end{array}$ & $\begin{array}{c}\Delta G^{0}(20) \\
(\mathrm{kJ} / \mathrm{mol})\end{array}$ & $\begin{array}{c}T \Delta S \\
(\mathrm{~kJ} / \mathrm{mol})\end{array}$ \\
\hline TT & $35.3 \pm 0.5$ & $-40.4 \pm 0.4$ & $-2.00 \pm 0.02$ & $-38.40 \pm 0.40$ \\
TA & $34.2 \pm 0.4$ & $-31.6 \pm 0.6$ & $-1.46 \pm 0.03$ & $-30.14 \pm 0.60$ \\
AA & $26.8 \pm 1.0$ & $-45.6 \pm 5.9$ & $-1.03 \pm 0.13$ & $-44.57 \pm 5.90$ \\
AGA & $29.6 \pm 0.8$ & $-40.5 \pm 2.8$ & $-1.28 \pm 0.09$ & $-39.22 \pm 2.80$ \\
\hline
\end{tabular}

$T_{m}$, melting temperature; $\Delta H_{V H}$, Van Hoff enthalpy changes; $\Delta G^{0}{ }_{(20)}$, changes of standard Gibbs energy at $20^{\circ} \mathrm{C} ; \Delta S$, entropy change $\left(\Delta G^{O T}=\Delta H_{\text {cal }}\left(1-T / T_{m}\right)=\Delta H_{V H}\left(1-T / T_{m}\right)=\Delta H_{V H}-T \Delta S\right.$; where $\Delta H_{\text {cal }}$ is calorimetric enthalpy. $\Delta H_{\text {cal }} / \Delta H_{V H}=1$ for two-state transition (Ohsen et al. 2009). Results are mean \pm SD $(n=3)$. (According to Lamberti et al. 2011). 
which took place were less favorable in comparison with TT aptamers. The AA aptamers demonstrated the highest level of instability; the favorable changes in enthalpy are in this case compensated by entropy contribution, changes which may be due to the uptake of ions or water into the G-quadruplex (Ohsen et al. 2009).

The lower values of $T_{m}$ in comparison with those reported by Ohsen et al. (2009) are due to the lower $\mathrm{KCl}$ concentration used, the presence of $\mathrm{NaCl}$ and the use of a thymine spacer.

The results of acoustic measurements obtained through the interaction of thrombin with aptamers immobilised on an acoustic thickness shear mode (TSM) transducer correlates with the thermodynamic properties of aptamers. The changes in the series resonant frequency $\left(f_{S}\right)$, responsible for mass changes and in motional resistance $\left(R_{m}\right)$, which reflects the viscosity contribution, were the most remarkable following the addition of thrombin to TT and AA aptamers. The $f_{S}$ value for both aptamers decreased with increasing thrombin concentrations, but these changes were substantially larger in TT aptamers which suggests a higher sensitivity to thrombin. Substantial differences were observed in changes of $R_{m}$ for these aptamers. While motional resistance rose with increasing thrombin concentrations in TT aptamers, opposite changes in $R_{m}$ took place for AA aptamers (Lamberti et al. 2011). This suggests the existence of different conformation-surface properties of the thrombin-aptamer complexes for these aptamers and, as a result, changes in the coupling of the surface and liquid. The data suggests a higher coupling for TT (increase in $R_{m}$ ), and a higher decoupling for AA (decrease in $R_{m}$ ) (Ellis and Thompson 2004). AGA aptamers had a lower sensitivity to thrombin in comparison with AA, but AT aptamers revealed comparable sensitivity with that of TT.

It is interesting to note that thymines are major nucleotides in the loops of telomeric sequences. The substitution of thymines in the loop TTA in the human telomeric sequence by adenines AAA resulted in destabilization of the quadruplex (Ristano and Fox 2003). One possible explanation for this is that pyrimidines $(\mathrm{T})$ which contain only one aromatic ring are more flexible in comparison with purines (A) which are composed of two rings.

The substantial structural polymorphism of G-quadruplexes has already been mentioned above; this polymorphism could be due to the length and composition of loop sequences, but other conditions, such as the ionic composition of the buffer solution and the aptamer concentration, could also affect quadruplex topography. TBA aptamers can be used as an example of this polymorphism. Most research has demonstrated that this aptamer is in an antiparallel chair conformation, although CD studies made at relatively high concentrations of aptamers (0.01-1 mM) have shown that G-quadruplexes of TBA sequence might form dimers
(Fialova et al. 2006). Similarly, aptamers sensitive to the heparin binding site have shown evidence of concentration dependent transition temperatures, which would reflect intermolecular interactions (Ponikova et al. 2008).

DNA aptamers composed of G-quadruplexes usually contain supporting sections which allow them to be immobilized on solid substrates and serve as recognition elements in biosensors (see below). This supporting part has resulted in a wider structural diversity of aptamers through the formation of aptamer dimers, as was discussed simultaneously by Hasegawa et al. (2008) and Hianik et al. (2008). Hasegawa et al. (2008) described two aptamers sensitive to fibrinogen and heparin binding sites of thrombin which contained poly dT linkers connected by DNA ligase. A similar approach was also used for the preparation of dimers from two identical aptamers against vascular endothelial growth factor $\left(V_{E G F}{ }_{165}\right)$. In our study, two identical TBA aptamers, from which one was modified by $\mathrm{dT}_{15}$ and $\mathrm{dA}_{15}$ linkers were used, and the dimer was formed by the hybridization of supporting $\mathrm{dT}_{15} \cdot \mathrm{dA}_{15}$ parts (Hianik et al. 2008). This work introduced the term "aptabody" for the aptamer dimer, suggesting an analogy between this structure and those of antibodies, as both contain two binding sites for the target. The same method was later applied to fibrinogen and heparin sensitive thrombin aptamers (Hianik et al. 2009). In these papers, we showed that the affinity of aptamer dimers to thrombin is superior to that of aptamer monomers which contain only one binding site. CD and gel electrophoresis studies including temperature gradient gel electrophoresis showed that G-quadruplexes are preserved in both binding sites of aptamer dimers. In addition, these dimers demonstrated levels of fibrinogen cleavage inhibition in thrombin which were almost twice as high as that of monomolecular aptamers (Ponikova et al. 2011). The existence of two binding sites in the dimers was also confirmed by single molecule force spectroscopy (Neundlinger et al. 2011), emphasizing that the substantial structural flexibility of aptamers is an additional advantage that makes these molecules excellent candidates for use as recognition elements in biosensors.

\section{Stability of guanine quadruplexes in DNA aptamers at presence of ions and the binding ligands}

It has already been mentioned that G-quadruplexes are stabilized by monovalent cations such as $\mathrm{K}^{+}$and $\mathrm{Na}^{+}$. The stabilizing effect of cations on G-quadruplex was most extensively studied in G-quadruplexes of TBA aptamers and it was shown that the formation of quadruplex structure in this aptamers requires the presence of $\mathrm{K}^{+}$ions (Kankia and Marky 2001; Trajkovski et al. 2009). Potassium is also required for the inhibition of thrombin-clotting (Wang et al. 1993; Tsiang et al. 1995). Aptamer quadruplex conformation 
is also stabilized in the presence of other cations (Wang et al. 1995; Smirnov and Shafer 2000; Kankia and Marky 2001); the presence of $\mathrm{Sr}^{2+}, \mathrm{Ba}^{2+}$ and $\mathrm{Pb}^{2+}$ was found to have a powerful stabilizing effect on G-quadruplexes (Smirnov and Shafer 2000; Kankia and Marky 2001), while sodium ions were shown to form markedly weaker binds to the aptamer (Kankia and Marky 2001; Nagatoishi et al. 2007).

The effect of cations on the stability of G-quadruplexes has been studied primarily through CD, UV spectroscopy, DSC and NMR methods. The TBA sequence is among most studied aptamers, and it has been shown that the stabilizing effect is reflected in the increasing melting temperatures of the quadruplexes. The monovalent cations stabilize the quadruplex in the order: $\mathrm{K}^{+}>\mathrm{Rb}^{+}>\mathrm{Na}^{+}>\mathrm{Cs}^{+}>\mathrm{Li}^{+}$. Divalent cations bind to quadruplexes with higher constants of association $\left(\mathrm{K}_{\mathrm{A}}\right)$ and the following order in stabilization was observed: $\mathrm{Sr}^{2+}>\mathrm{Ba}^{2+}>\mathrm{Ca}^{2+}>\mathrm{Mg}^{2+}$ (Hardin et al. 2000; Tucker et al. 2012). However, the localization of ions in the quadruplex and the stoichiometry of binding are not yet fully clear and, in certain cases, controversial results have been reported. Researches using NMR (Marathias and Bolton 2000), infrared multiphoton dissociation (IRMPD) and CD methods (Hong et al. 2010) to study the TBA sequence have shown that the most likely form of 1:2 (TBA to $\mathrm{K}^{+}$) stoichiometry is that which is depicted schematically in Fig. 1C. The first $\mathrm{K}^{+}$ion binds between TT loops and the second is localized at the TGT loop; in contrast, recent NMR studies suggest that $\mathrm{K}^{+}$is localized between the G-quartet planes (Fig. 1D) (Trajkovski et al. 2009). Interestingly, this localization had been proposed previously for $\mathrm{Pb}^{2+}$ which also induces TBA folding (Smirnov and Shafer 2000). In contrast with $\mathrm{K}^{+}$ions, smaller cations like $\mathrm{Na}^{+}$are localized at the plane of G-quartets (Fig. 1E) (see Schultze et al. 1999 and a recent review by Tucker et al. 2012). It is likely that cation localization correlates with the ionic radius (Kankia and Marky 2001).

It should be noted that G-quadruplex folding can also be induced by the binding of the target, e.g. thrombin in the case of TBA, a process which has been confirmed using $\mathrm{CD}$ spectroscopy. The presence of $5 \mu \mathrm{M}$ of thrombin induced the formation of G-quadruplexes even without the presence of stabilizing ions. Quadruplex folding can also be influenced by crowding with the dehydrating agents, e.g. polyethylene glycol (PEG200) and ethanol (Renciuk et al. 2009). A decrease in temperature also supports the formation of G-quadruplexes in the absence of cations (Nagatoishi et al. 2007).

The issue of the high sensitivity of the TBA sequence to various cations is raised in research focused on the detection of $\mathrm{K}^{+}$(Choi et al. 2009; Cai et al. 2010), $\mathrm{Pb}^{2+}$ and $\mathrm{Hg}^{2+}$ (Liu et al. 2009; Li et al. 2010) using various physical methods. TBA sequences were also incorporated in nanopores formed by $a$-hemolysin ( $\alpha \mathrm{HL}$ ) in bilayer lipid membrane; the addi- tion of cations, especially $\mathrm{K}^{+}$, resulted in the folding of TBA into quadruplexes and reduced the current flowing through the nanopore (Shim et al. 2009). In the detection of ions by aptamers it is important to determine their binding affinity, which can be usually characterized by the constant of dissociation $\mathrm{K}_{\mathrm{D}}\left(\mathrm{K}_{\mathrm{D}}=1 / \mathrm{K}_{\mathrm{A}}\right)$. The lower $\mathrm{K}_{\mathrm{D}}$ value corresponds to a higher affinity or stability of the ion-quadruplex assembly. The $\mathrm{K}_{\mathrm{D}}$ value can be determined from the binding isotherm using CD spectroscopy and measuring the amplitude of the corresponding band as a function of ion concentration; in the case of TBA or other antiparallel G-quadruplexes, the band at around $295 \mathrm{~nm}$ can be used. In our study (Ponikova et al. 2008), we determined $K_{D}$ values connected with both the binding of $\mathrm{K}^{+}$to TBA G-quadruples and to the quadruples in which $\mathrm{T}_{4}$ was substituted by $\mathrm{A}_{4}$ and in which the TGT loop was replaced by a GCA sequence (see Fig. 1B for the nucleotide sequence of TBA). The structure of this modified aptamer (HEPA) contains a heparin-sensitive binding site at thrombin (Tasset et al. 1997). In contrast with TBA, the properties of HEPA have not yet been studied in great detail. Simultaneously, it has been pointed that the above mentioned substitutions of nucleotides in the loops of HEPA are likely to have a detrimental effect on the structure of the quadruplex. Since it is no longer possible to form base pairs between thymines at positions 4 and 13 in HEPA, some additional stabilizing factors are needed (Macaya et al. 1993), and it has therefore been suggested that flanked sequences of spacers and duplex of 29-mer should be included in order to improve the stability of the quadruplex core (Tsiang et al. 1995; Tasset et al. 1997). However, we have shown that even without the flanking sequence the G-quadruplex of HEPA is stable in the presence of $\mathrm{K}^{+}$ions, and it has also been proven that potassium has a similar effect on both TBA and HEPA aptamers and that it can also stabilize the G-quadruplex structure. However, weaker binding of potassium to HEPA can be observed in the presence of sodium ions, whereas the TBA- $\mathrm{K}^{+}$complex is only slightly affected (Ponikova et al. 2008).

In the $\mathrm{K}^{+}$binding studies, the analysis of our $\mathrm{CD}$ experiments based on Hill equation showed that $\mathrm{K}^{+}$binds to the aptamers not co-operatively, i.e. the Hill coefficient $\mathrm{m}=1$ (see Dovinova and Hianik 1990; Weiss 1997). The plot of normalized ellipticity at $292 \mathrm{~nm}$ as a function of $\mathrm{K}^{+}$ ion concentration took the shape of a Langmuir isotherm (Fig. 4) and thus can be described clearly using a Langmuir equation:

$$
\Delta \theta / \theta_{0}=\frac{\left(\theta_{\max } / \theta_{0}-1\right)\left[K^{+}\right]}{K_{D}+\left[K^{+}\right]}
$$

where $\Delta \theta=\theta-\theta_{0}, \theta$ is ellipticity at $292 \mathrm{~nm}$ and at corresponding equilibrium concentration of potassium ions, 
$\left[\mathrm{K}^{+}\right], \theta_{0}$ is ellipticity of initial state, $\theta_{\max }$ is ellipticity of final state of titration (at saturation). The free energy of potassium binding can be calculated using a standard Gibbs equation $\Delta \mathrm{G}=-\mathrm{RT} \cdot \ln \mathrm{K}_{\mathrm{A}}$. The binding curves for TBA and HEPA were similar (Fig. 4), although the broader curve for HEPA suggests weaker binding of potassium ions to the quadruplexes.

Based on Eq. (2) we estimated dissociation constants and determined changes in Gibbs energy $(\Delta G)$. These values are presented in Table 3. As can be seen from this table, at $T=$ $25^{\circ} \mathrm{C}$ the dissociation constant for TBA is approx. four times lower than that recorded for HEPA, which suggests that TBA- $\mathrm{K}^{+}$may enjoy higher stability than HEPA.

$\Delta G$ values determined for the TBA aptamer correspond to data published by Kankia et al. (2005) in which isothermal titration calorimetry was used to determine the thermodynamic parameters for TBA quadruplex folding. For the HEPA aptamer, the $\Delta G$ value was estimated at $-18.0 \mathrm{~kJ} / \mathrm{mol}$ and reflects a more subtly hindered $\mathrm{K}^{+}$-mediated formation of quadruplex in comparison with TBA. As can be seen in the table, lower temperatures have a favorable effect on the formation of aptamer-potassium complexes as is shown by the increase in $\Delta G$ absolute value for both aptamers. In the presence of sodium ions, the changes in $\Delta G$ were more remarkable. The affinity of the TBA aptamer to $\mathrm{K}^{+}$at $15^{\circ} \mathrm{C}$ was only slightly affected by $\mathrm{Na}^{+}$. However, HEPA exhibited unfavorable changes in the presence of $\mathrm{Na}^{+}$both in terms of $K_{D}$ and of $\Delta G$. Table 3 demonstrates that sodium ions inhibit interaction with $\mathrm{K}^{+}$, which in turn results in an increase in $K_{D}$ and a decrease in the absolute value of $\Delta G$. This observation supports previous studies which have suggested that the presence of adenosines in telomeric sequences affects quadruplex formation and its affinity to sodium and potassium ions (Guo et al. 1992).

\section{G-quadruplex DNA aptamers}

Aptamers display a wide range of structural arrangements which account for their binding efficiency and selectiv-

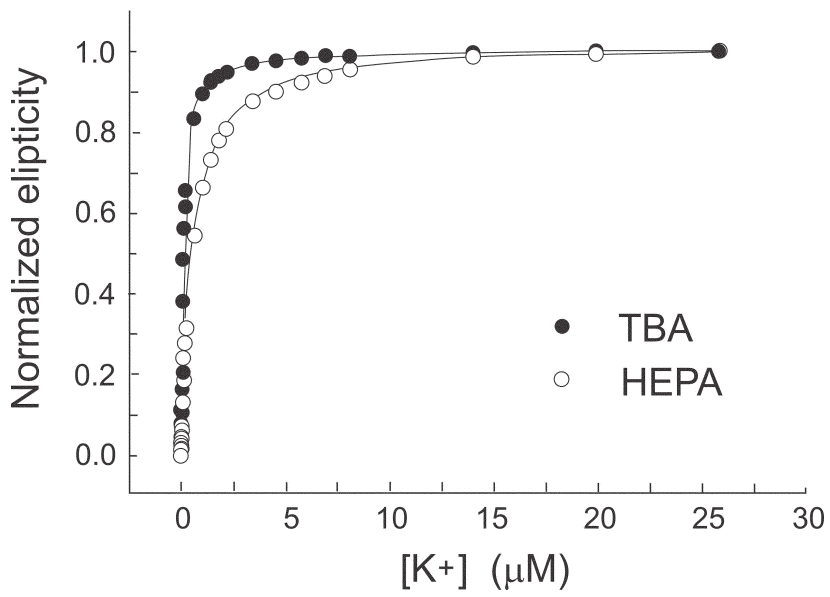

Figure 4. The Langmuir plot of normalized amplitude of CD spectra at $292 \mathrm{~nm}$ as a function of concentration of $\mathrm{K}^{+}$for TBA (•) and HEPA (O) aptamers. The symbols represent experiments and the full lines represent fit according to Eq. (2). The concentration of aptamers was $10 \mu \mathrm{M}$ (according to Ponikova et al. (2008) with permission of Gen. Physiol. Biophys.).

ity for unrelated targets. As with several architectures of G-rich short nucleic acids, the G-quadruplex is adopted by a number of aptamers. Certain G-rich oligomers may associate between themselves and form inter-molecular G-quadruplex structures. One common feature of G-quadruplexes is that they can exhibit high conformational stability and resistance to various nucleases (Dapic et al. 2003), which indicates that these novel G-quadruplex-based molecules have great potential for use in medicine and biotechnology. G-quadruplexes are particularly interesting in this respect because it has been suggested that G-rich sequences in the human genome, such as telomere ends (Parkinson et al. 2002; Neidle and Parkinson 2003), oncogenic promoters (Siddiqui-Jain et al. 2002; Ambrus et al. 2005) and many other regions associated with human diseases (Fry and Loeb 1994) may form such structures in vivo. Despite the intense speculation over the physiological role

Table 3. The constant of dissociation, $K_{D}$, and changes of Gibbs energy, $\Delta G$, connected with formation of guanine quadruplexes of TBA and HEPA aptamers in the presence of potassium and sodium ions determined from Langmuir isotherms according to Eq. (2) and Gibbs equation $\Delta G=-\mathrm{RT} \ln K_{A}$, where $K_{A}=1 / K_{D}$

\begin{tabular}{lccccc}
\hline \multirow{2}{*}{ Buffer composition } & \multirow{2}{T}{} & \multicolumn{2}{c}{ TBA } & \multicolumn{2}{c}{ HEPA } \\
\cline { 3 - 6 } & $\left({ }^{\circ} \mathrm{C}\right)$ & $K_{D}(\mu \mathrm{M})$ & $\Delta G(\mathrm{~kJ} / \mathrm{mol})$ & $K_{D}(\mu \mathrm{M})$ & $\Delta G(\mathrm{~kJ} / \mathrm{mol})$ \\
\hline $10 \mathrm{mM}$ Tris- $\mathrm{HCl}$ & 25 & $130 \pm 1.0$ & $-22.1 \pm 0.2$ & $540 \pm 5.0$ & $-18.0 \pm 0.2$ \\
$10 \mathrm{mM}$ Tris-HCl & 15 & $30.0 \pm 1.0$ & $-24.9 \pm 0.8$ & $180 \pm 10.0$ & $-20.6 \pm 1.1$ \\
$20 \mathrm{mM}$ Tris- $\mathrm{HCl}+140 \mathrm{mM} \mathrm{NaCl}$ & 15 & $35.0 \pm 0.3$ & $-24.5 \pm 0.2$ & $3350 \pm 250$ & $-13.6 \pm 1.0$ \\
\hline
\end{tabular}

The $\mathrm{pH}$ of buffers was 7.4. Results represent mean \pm SD obtained from 3 independent experiments in each series (according to Ponikova et al. 2008 with permission of Gen. Physiol. Biophys.) 
of G-quadruplex formation in vivo, there is considerable interest in the therapeutic potential of quadruplex oligonucleotides as aptamers or non-antisense anti-proliferative agents. Many authors have demonstrated that several short G-rich oligomers can inhibit cell proliferation and induce apoptosis in cancer cell lines; the activity of these oligomers was related to their ability to bind to specific cellular proteins (Dapic et al. 2002, 2003; Bates et al. 2009).

The intrinsic properties of G-quadruplexes containing aptamers make them one of most efficient sensing elements for target molecule recognition. It has been suggested that DNA aptamers with high affinity and specificity for tumor marker proteins could be of use in the sensitive and accurate diagnosis of a number of diseases. Furthermore, some aptamers inhibit the activities of their target molecules, a trait which could be used as a tool for the control of any molecular process (Hirao et al. 2000; Noma et al. 2006; Allali-Hassani et al. 2007). Aptamers based on G-quadruplex structures have great diagnostic and therapeutic potential for the detection and treatment of severe pathologies including vascular, cancer and viral diseases (Ruckman et al. 1998; Keefe et al. 2010).

Although a large number of aptamers have been identified, only a few of them belong to the very small group which can form G-quadruplex motifs. The best known of these aptamers is the thrombin binding aptamer (TBA) (Padmanabhan et al. 1993), an aptamer which exhibits inhibitory properties towards pharmacologically relevant proteins. To date many sequence variants of the TBA aptamer have been developed, e.g. modified TBAs carrying uridine (U), 20-deoxy-20-fluorouridine (FU), North-methanocarbathymine (NT) residues and thio-modifications in the loop regions or dimeric variants containing double stranded connective stems (Hianik et al. 2008; Zaitseva et al. 2010; Ponikova et al. 2011; Aviñó et al. 2012). The aptamer-target complex is often more stable than an individual aptamer; recently published research shows that the TBA-thrombin complex is more stable than TBA itself (Russo Krauss et al. 2012). G-quadruplex aptamers may also inhibit functions of other proteins such as HIV1-integrase (HIV1-in) (Jing and Hogan 1998; Jing et al. 2000; De Soultrait et al. 2002), VEGF, (Vap7) (Nonaka et al. 2010) and nucleolin (AS1411) (Reyes-Reyes et al. 2010). Their DNA sequences are summarized in Table 1. For example, the DNA aptamer AS1411 is currently undergoing clinical evaluation for use in the treatment of acute myeloid leukemia.

\section{DNA aptamers in medical therapy and drug delivery}

Both DNA and RNA aptamers have great potential for use in medical therapy and may eventually replace the antibodies which are currently used in immunotherapy. Aptamers have a number of distinct advantages over antibodies; they can be reliably duplicated in vitro in the precise volumes required, and, through the use of simple chemical modification, they can be protected from degradation by nucleases and have their lifespan in blood extended by up to 24 hours without major side effects. Aptamers can also be used as carriers of a wide range of medical drugs through their ability to be attached to various nanoparticles; aptamers which are sensitive to, for example, cancer markers on the surface of cancer cells can provide targeted delivery of chemotherapeutic or other drugs (Cerchia and de Franciscis 2010). The RNA aptamer Macugen, which was approved for clinical use in 2004, is very effective in the treatment of the devastating disease of age-related macular degeneration. This chemically modified RNA aptamer binds specifically to VEGF, thereby protecting the binding of VEGF to its receptor and inhibiting the growth of the blood vessels (Foy et al. 2007; Potty et al. 2009). Other aptamers are currently in clinical trials. The application of DNA and RNA aptamers in medical therapy was recently reviewed by Bunka et al. (2010). Although not all aptamers which show potential for use in therapy contain G-quadruplexes, DNA aptamers containing G-quadruplexes have the advantage of the added stability provided by these structures. The various applications of G-rich aptamers in medical therapy have been reviewed recently (Tucker et al. 2012), and therefore this review will limit itself to a brief summary of the most important applications.

The aptamers which are currently undergoing clinical trials or which show potential for use as therapeutic agents are listed in Table 1. TBA was among the first aptamers to be specially developed for medical application in 1992 and could eventually replace heparin as a new type of anticoagulant; as was mentioned above, TBA specifically binds to the fibrinogen binding site at thrombin thereby inhibiting fibrinogen cleavage (see Becker et al. 2010 for detailed review).

A second group of aptamers have been developed for the treatment of infectious diseases with particular focus on HIV. Aptamers include those which exhibit sensitivity to envelope Gp120 protein (Wyat et al. 1994), HIV integrase (Chou et al. 2005 and references herein) and HIV reverse transcriptase (Michalowski et al. 2008 and references herein). The dissociation constant of these aptamers was in the nM range (see Table 1 for nucleotide sequence of aptamers). Guanine-rich DNA aptamers were also selected for Hepatitis C virus (Jones et al. 2006), SARS coronavirus (Shum and Tanner 2008) and against polyphosphate kinase 2 from Mycobacterium tuberculosis (Shum et al. 2011a).

Aptamers can be selected not only for proteins or other ligands dissolved in a buffer, but also to proteins which are connected to the cell surface. Cancer cells are known to have specific proteins in their membranes and certain proteins are overexpressed in cancer cells. Proteins such as 
nucleolin, prostate-specific membrane antigen (PSMA) and others (see Phillips et al. 2008; Orava et al. 2010 for detailed review) can serve as cancer markers. Several DNA and RNA aptamers which selectively bind to cancer markers have been developed, although not all of them contain G-quadruplexes. Among these G-rich cancer marker-sensitive aptamers is AS1411, which selectively binds to nucleolin,and which is currently in phase II of clinical trials for use as an anticancer drug for the treatment of renal cell carcinoma and myeloid leukemia (Bates et al. 2009). AS1411 may also be used for the targeted delivery of drugs to cancer cells through nucleolinmediated internalisation (Shieh et al. 2010).

A G-rich aptamer which selectively binds to sclerosin, an extracellular negative regulator of bone growth and a major therapeutic target for osteoporosis, has also recently completed phase II of clinical testing. This DNA aptamer which contains a parallel quadruplex structure could eventually be used in the treatment of skeletal diseases (Shum et al. 2011b).

\section{DNA aptamers containing G-quadruplexes in biosensors}

Aptamers are also of great use in the development of biosensors (aptasensors). A biosensor can be defined as a device which contains a recognition element of a biological nature or as a transducer which can transform a biochemical reaction into a measureable physical signal, usually optical or electrical (Eggins 2004). A biosensor is connected to an analyzer, such as an electrochemical, optical or acoustical unit, which can allow the determination of a quantitative relation between the concentration of the analyte and the measurable physical signal. The first generation of biosensors was based on enzymes such as glucose oxidase which served as recognition elements; the amperometric glucose sensor is currently the most successful practical biosensor in use. The presence of a substrate, e.g. glucose, results in its catalytic degradation into species which can be reduced or oxidized at the sensing electrode. A new generation of the biosensors is currently in development, for example, affinity biosensors which utilize various recognition elements, such as antibodies, nucleic acids and natural or synthetic receptors such as calixarenes.

The recognition molecule - the receptor - is the most important part of the biosensor. Receptors should have sufficient affinity to the analyte (usually in pM to nM range), and should also be stable and regenerable; they should also have the ability to be immobilized on the transducer surface without loss of recognition properties. Antibodies are currently the most widely used receptors in affinity biosensors, but they have a number of drawbacks. They are unstable, usually requiring replacement after only one analysis, and they require special care in immobilization. They also ex- hibit a somewhat random attachment to surfaces which may block some binding sites and thus reduce the sensitivity of measurements. The regeneration of antibodies on the sensor surface is rather complicated and after treatment with glycine or other regeneration protocols usually results in reduced sensitivity. Perhaps the most serious drawback of antibodies is laborious animal-derived production process which is both costly and renders impossible the development of antibodies sensitive to certain analytes such as, for example, toxins. Other systems such as natural receptors could be an alternative, but their low stability and specific environmental requirements are problematic. Synthetic receptors such as calixarene can overcome the above mentioned difficulties, but their sensitivity to the analyte relative to that of antibodies is disappointingly low.

Aptamers have a number of distinct advantages over other types of biosensors. They exhibit a high affinity level which is comparable to and in some cases even higher than those of antibodies; they also demonstrate high levels of stability, and can be easily regenerated in specific conditions, for example in high ionic strength. The flexibility of aptamers is a huge advantage and they can undergo a wide range of chemical modifications without any appreciable loss of affinity; for example, aptamer sensing sequences can be extended by a oligonucleotide spacer the end of which can be modified by thiol, amino, carboxyl group or by biotin, allowing their immobilization on various surfaces, such as gold, carbon nanotubes, graphene, biomimetic lipid membranes and others.

In terms of signal transduction, biosensors can be divided into 3 major groups: electrochemical, optical and acoustical. Electrochemical aptasensors are based on the immobilization of aptamers on a conducting surface, such as gold, carbon nanotubes, graphene, conductiong polymers, etc. The binding of analyte to aptamer is monitored by measuring current, potential or impedance. The main advantage of this approach lies in the possibility of label-free detection (Mairal et al. 2008; Cheng et al. 2009; Ferapontova and Gothelf 2011). Optical aptasensors utilize aptamers labeled with optical probes (for example, fluorescence) or are attached to optically active nanoparticles. Label free detection is also possible using surface plasmon resonance method (SPR) (Tombeli et al. 2005; Shevchenko et al. 2011). Acoustical biosensors are highly convenient label-free detection systems. The aptamers are immobilized on an acoustical transducer, the most popular of which is the AT cut quartz (Bini et al. 2007). The interaction of the analyte with the aptamers results in changes to the properties of surface layers, typically mass and surface viscosity, which in turn cause changes of series resonant frequency, $f_{S}$, which reflects the mass changes and motional resistance, $R_{m}$, responsible for surface viscosity effect (Šnejdarková et al. 2008). The main advantage of this technique is its relative low cost in comparison with that of other methods. 
Although the use of aptamers in biosensing started only recently (Scheller et al. 2001), the field is currently growing very rapidly and a wide range of DNA and RNA aptamers have been developed for use as biosensors. Not all of these aptamers feature G-quadruplexes (for example aptamers sensitive to cellular prions, IgE, cocaine and others), but nonetheless G-rich aptamers are of special interest for a number of reasons. Firstly, G-quadruplexes increase the resistance of aptamers to nucleases. Secondly, twice higher charge density of quadruplex in comparison with unfolded single stranded DNA facilitates interaction of analyte containing positive patches. Thirdly, the ability of ions or analytes to induce folding of quadruplexes provides additional assay (Shim et al. 2009). Finally, G-quadruplexes can bind to various small molecules such as cholesterol (Li et al. 2012) or fluorescence dyes thus widening the range of potential analytical applications (Shi et al. 2011). Reviews of aptasensors based on G-rich aptamers have been published recently by Lv et al. (2012) and by Tucker et al. (2012); therefore our study will restrict itself to electrochemical and acoustical aptasensors based on G-quadruplex containing DNA aptamers sensitive to human thrombin. Aptasensors for thrombin detection are among the most studied of aptasensors and can serve as a model system for optimization of aptamer immobilization on surfaces and of detection strategies for other targets.

As was discussed above, thrombin is a multifunctional serine protease that plays an essential role in pro-coagulant and anti-coagulant functions. High concentrations of thrombin induce thrombosis, while thrombin deficiency can cause excessive bleeding (Berliner 1992). Aptasensors which function as alternative diagnostic tools for thrombin analysis or blood coagulation using nanomolar detection could be of great use in medical research. DNA aptamers sensitive to fibrinogen and heparin binding sites of thrombin have been used successfully in the development of biosensors and in signal amplification. In the sandwich assay reported by Ikebukuro et al. (2005), thiolated capture 15-mer TBA aptamers were immobilised on a gold surface through chemisorption. Another reported 29-mer aptamer sensitive to heparin binding site at thrombin was linked to pyrroquinoleine quinine glucose dehydrogenase (PQQGDH). The addition of the substrate (glucose) resulted in a current being detected by chronoamperometry, and a limit of detection (LOD) of 10 $\mathrm{nM}$ with a 40-100 nM linear range was achieved. Three methods of electrochemical assay for thrombin detection were proposed by Mir et al. (2006), and the best LOD recorded $(5 \mathrm{nM})$ was achieved using a sandwich competitive assay which involved aptamers labeled with the enzyme horseradish peroxidase (HRP) (Mir et al. 2006). It has been pointed out that this LOD would be sufficient for the clinical diagnosis of metastatic lung cancer in which the concentration of thrombin is $5.4 \mathrm{nM}$. However, the drawbacks of this method could be the non-specific binding of thrombin to the gold surface and the difficulties involved in applying this assay format in blood due to the presence of other proteins.

Several aptasensors intended for use in the direct electrochemical detection of thrombin have been based on electrochemical redox indicators, such as methylene blue $(\mathrm{MB})$ or ferocene $(\mathrm{Fc})$. The indicator undergoes an oxidation and reduction transition due to electron transfer from the electrode surface to a probe. This simple and effective approach is based on the fact that positively charged MB interacts with negatively charged proteins or other negatively charged analytes (Fig. 5A). In the presence of $\mathrm{MB}$ which
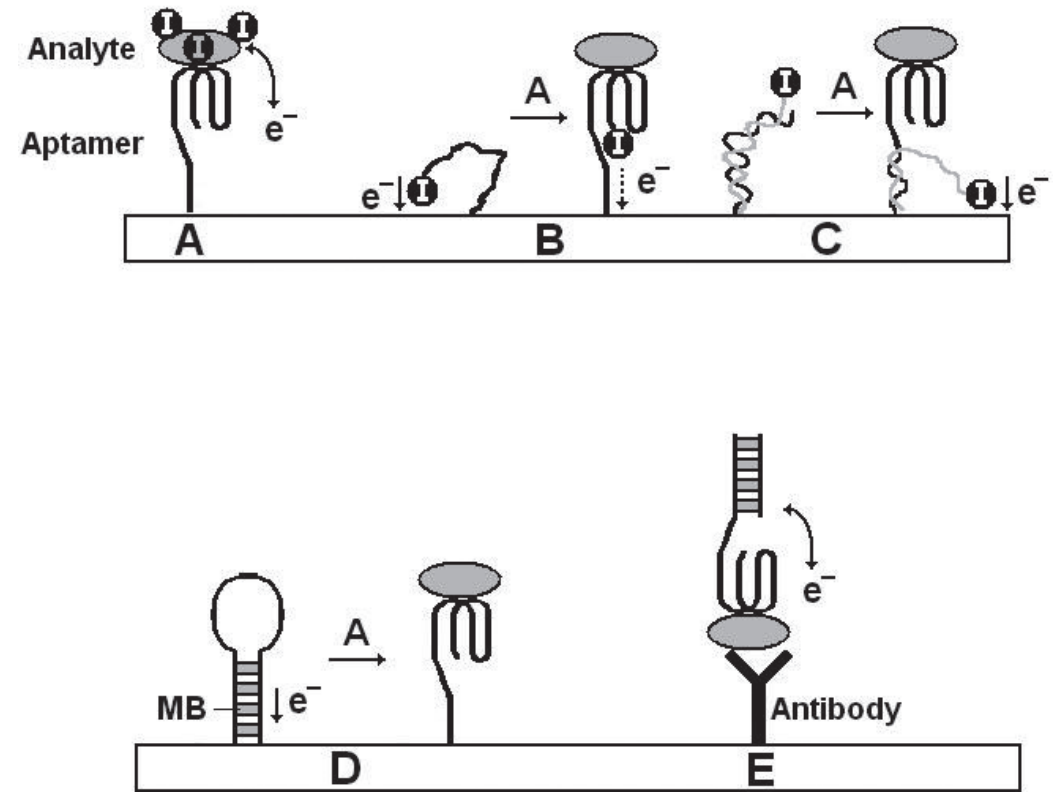

Figure 5. Schematic representation of the aptasensor design that utilize electrochemical indicators (I) as a redox probe. A. Positively charged indicator (for example methylene blue (MB)) forms complexes with analyte. Binding of analyte to the aptamer caused the appearance of redox current. B. Binding of analyte caused conformational changes of the aptamers and increase of the distance of the probe from the electrode surface. C. Aptasensor is formed by aptamers and complementary DNA strand modified by indicator. Addition of analyte resulted in partial disintegration of the double helix, which deliberates the DNA end modified by redox probe. $\mathbf{D}$. Aptasensor is based on intercalation of MB into double helix. Addition of analyte resulted in double helix disintegration and in decrease of the redox current. E. Sandwich assay utilizing specially designed aptamers with intercalated $\mathrm{MB}$ as a probe. A, analyte; I, electrochemical indicator (according to Hianik and Wang (2009) with permission of Wiley-VCH). 
forms complexes with the analyte, an increased redox current is observed when the analyte binds to the aptamers immobilized on the electrode surface. In experiments, the current corresponding to a reduction of $\mathrm{MB}$ is measured by differential pulse voltammetry (DPV). The peak integration allows for calculating the changes in the charge transfer. The plot of the relative charge transfer as a function of protein concentration is determined and it serves as a calibration curve. An example of this calibration curve and DPV plot is presented in Fig. 6; the data is taken from an aptasensor based on thrombin specific DNA aptamers utilizing MB as indicator. This approach allowed detection thrombin with a LOD of $10 \mathrm{nM}$ (Hianik et al. 2005).

Another approach is based on the ability of aptamers to switch conformation in the presence of the analyte which allows rapid label-free electrochemical detection. The process of binding an analyte to the oligonucleotide probe changes its structure and dynamics thereby influencing the efficiency of electron transfer to the electrode surface. MB has also been integrated into a "signal off" design which has been described by Xiao et al. (2005a). In the absence of an analyte, a redox current was observed due to random configurations of aptamers and the close proximity of $\mathrm{MB}$ to the gold surface. The addition of the analyte (thrombin) resulted in changes in aptamer conformation, which caused an average increase in the distance of MB from the electrode surface and a decrease of the current with increasing thrombin concentrations (Fig. 5B). This sensor was capable of detecting at least $6.4 \mathrm{nM}$ of thrombin in addition to a dynamic linear response of up to $768 \mathrm{nM}$, a range which would allow detection of the physiologically relevant thrombin concentrations which range from a few $\mathrm{nM}$ (resting blood) to several hundred nM (when the clotting cascade is activated). The same laboratory has also reported a "signal on" design for a thrombin aptasensor (Xiao et al. 2005b) in which a thiolated thrombin binding aptamer was immobilized on a gold support. The addition of complementary DNA strand modified at one end with $\mathrm{MB}$ resulted in a double helix construction. The addition of thrombin caused conformational changes in the aptamer and the partial disintegration of the double helix, which release the DNA end modified by MB. Due to this conformational change, the MB approaches the sensor surface and an increased current was recorded (Fig. 5C). The LOD for this sensor was around $3 \mathrm{nM}$ (see also Hianik and Wang (2009) for a review of aptasensors based on electrochemical indicators).

$\mathrm{MB}$ is also known as a DNA intercalator (Boon et al. 2000). MB intercalation into DNA enhances electron transport through the double helix, a peculiarity which has been exploited in aptasensor design. The extension of one end of an aptamer with a oligonucleotide sequence which is complementary to a specific part of the second end of the aptamer resulted in the formation of a so-called molecular

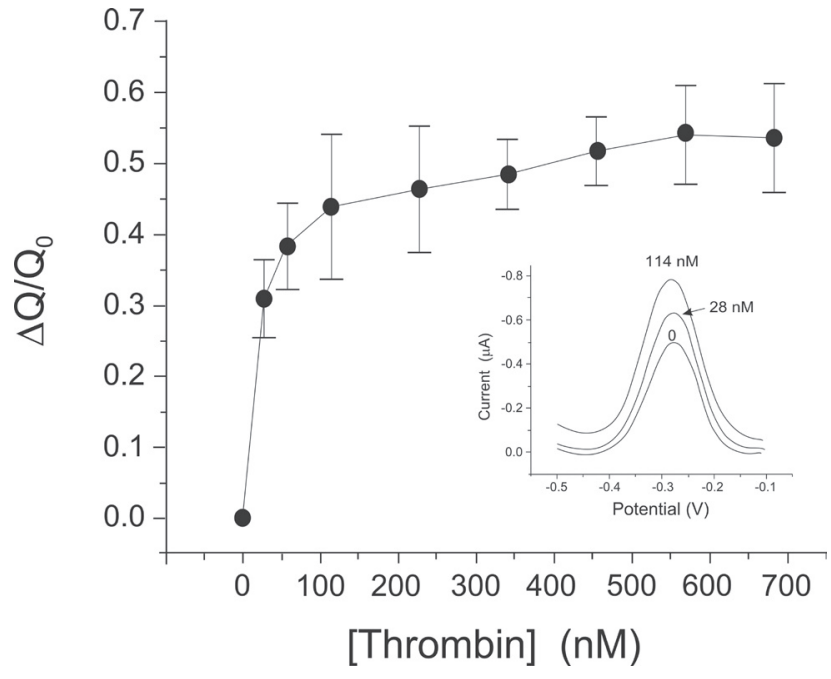

Figure 6. Example of calibration plot for thrombin sensitive aptasensor based on electrochemical indicator methylene blue (MB): The relative changes of the maximum charge transfer, $\Delta \mathrm{Q} / \mathrm{Q}_{0}, \mathrm{Q}_{0}$ is the charge transfer without thrombin and $\mathrm{Q}$ is the charge transfer at certain thrombin concentration) are plotted as a function of thrombin concentration. Full line is the fit constructed by nonlinear least squares algorithm. According to the Langmuir equation. The dissociation constant determined from the fit. $\mathrm{K}_{\mathrm{D}}=36 \pm 5 \mathrm{nM}$. Inset: example of DPV for aptasensor without thrombin and at presence of two concentrations of thrombin: $28 \mathrm{nM}$ and $114 \mathrm{nM}$ (according to Hianik et al. (2005) with permission of Elsevier).

beacon. The addition of an analyte resulted in the depletion of the double helix, a process which stabilized the molecular beacon and transformed the aptamers into a 3D hairpin conformation. If the molecular beacon contains intercalated $\mathrm{MB}$, the transition of the aptamers in the presence of the analyte will result in a decrease in electron transport (Bang et al. 2005) (Fig. 5D). MB intercalation has been used also in a sandwich format aptamer biosensor (Kang et al. 2008). The thrombin-specific antibody was immobilized on a nanoparticle-chitosan composite film. After the addition of thrombin and system stabilization, the thrombin specific aptamers containing double helical sections with intercalated $\mathrm{MB}$ at its terminal region were added. The presence of $\mathrm{MB}$ resulted in an increase in the redox current which rose with increasing thrombin concentrations (Fig. 5E). An LOD of $0.5 \mathrm{nM}$ was recorded for this aptasensor.

Another highly sensitive method of amperometric thrombin detection is based on the redox indicator neutral red (NR) being covalently attached to specially synthesized polycarboxylated thiacalix[4] arene (Evtugyn et al. 2012). The calixarenes were immobilized on an electropolymerized layer of NR which, together with a TBA aptamers, were modified by an amino group and covalently attached to an EDC/NHS (1-Ethyl-3-[3-dimethylaminopropyl]carbodiimide hydro- 


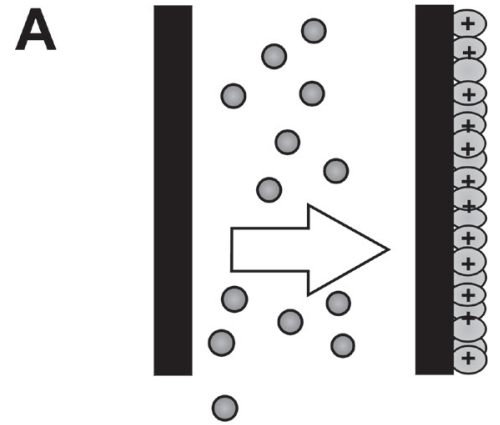

Electropolymerization
Thiacalixarene $\mathbf{A}$

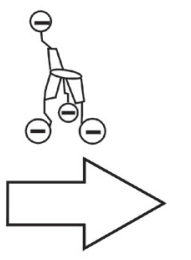

Electrostatic Accumulation

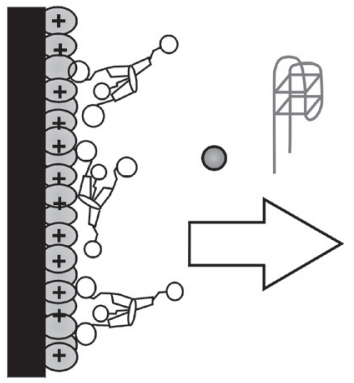

$\mathrm{NR}+$ Aptamer Carbodiimide Binding

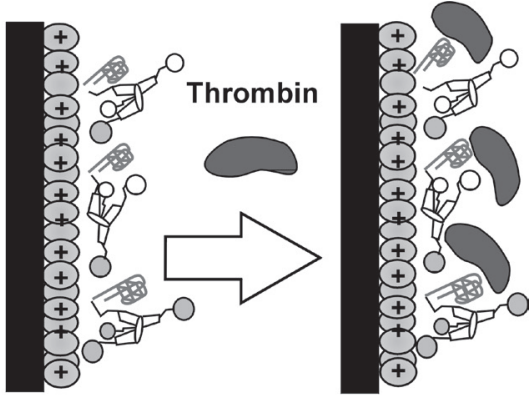

Incubation in Thrombin Solution
B
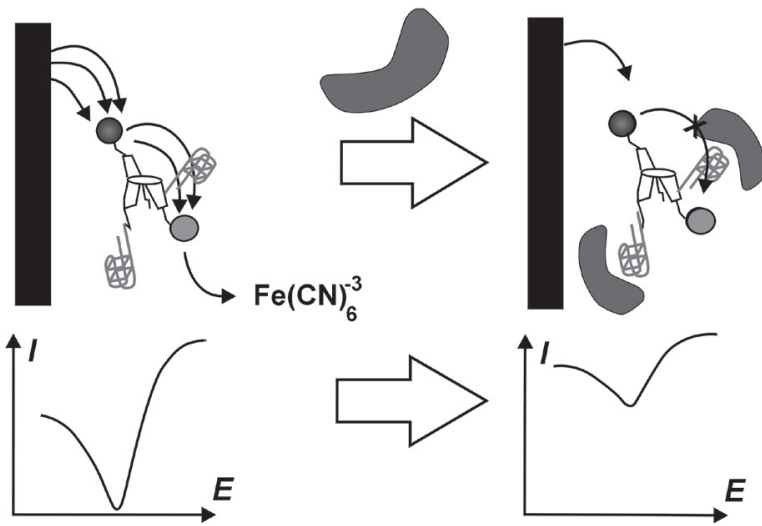

Figure 7. A. The scheme of the aptasensor assembling by means of electropolymerised layer of neutral red (NR) at glassy carbon electrode and thiacalixarenes. B. Principles of amperometric detection of thrombin (according to Evtugyn et al. (2012) with permission of Wiley-VCH). chloride / N-Hydroxysuccinimide) activated calixarene surface (Fig. 7A). The NR reduction current recorded after 10 min incubation fell with increasing thrombin concentrations

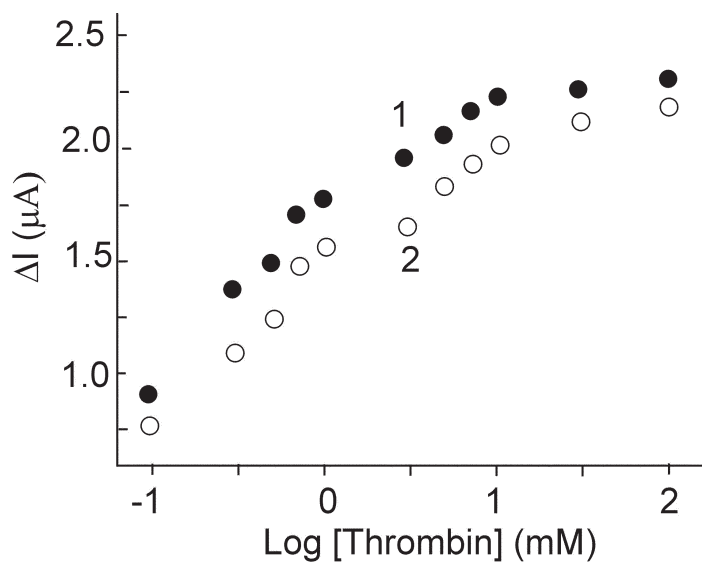

Figure 8. The calibration curve of thrombin detection by biosensor based on DNA aptamers immobilised on thiacalixarenes (Fig. 7) in a complex biological fluids: 1, in 10 times diluted blood plasma; 2 , in the presence of $30 \mathrm{mM}$ bovine serum albumin (BSA) in 0.05 M TRIS buffer solution, pH 7 (according to Evtugyn et al. (2012) with permission of Wiley-VCH). due to the limitation of the electron exchange on the surface layer (Fig. 7B). The aptasensor allows the determination of 0.1-50 nM of thrombin (limit of detection $0.05 \mathrm{nM}$ ). The aptasensor could be used for the direct determination of thrombin in blood serum as it does not exhibit any alteration of response in the presence of a 100 fold excess of serum proteins (Fig. 8).

Impedance spectroscopy has also been used as a technique for the label-free detection of ligand-aptamer interactions. Rodrigez et al. (2005) and Radi et al. (2006) simultaneously reported the application of electrochemical impedance spectroscopy (EIS) in the detection of interactions between proteins and DNA aptamers. The detection method is based on the measurement of charge transfer resistance, $\mathrm{R}_{\mathrm{ct}}$, in the presence of a redox mediator $\left[\mathrm{Fe}(\mathrm{CN})_{6}\right]^{-3 /-4}$. In the absence of the target protein, the negatively charged aptamer repels the redox mediator molecules from the sensor surface (Fig. 9A). The protein binding resulted in attraction (for positively charged proteins such as lysozyme) or repulsion (for negatively charged proteins such as thrombin) of the mediator to the surface and the decrease or increase, respectively, of $\mathrm{R}_{\mathrm{ct}}$. The value of $R_{c t}$ can be determined from the analysis of the Nyquist plot using a corresponding equivalent circuit. This plot for bare gold with immobilized aptamers and at presence of $20 \mathrm{nM}$ of thrombin is shown on Fig. 9B. It can be seen in 
typical semicircles and linear part. The diameter of semicircle is proportional to $\mathrm{R}_{\mathrm{ct}}$, while the linear part corresponds to the diffusion/limited process. Radi et al. (2006) described a process, in which a thiol modified anti-thrombin aptamer and 2-mercaptoethanol were immobilized on a gold electrode thereby blocking the surface from non-specific adsorption. This sensor was capable of detecting $2 \mathrm{nM}$ of thrombin with a linear range of 5-35 $\mathrm{nM}$; the sensor could also be regenerated through the application of $2 \mathrm{M}$ of $\mathrm{NaCl}$. Rodrigez et al. (2005) used a similar process in the detection of lysozyme using a modified aptamer; in this case, the charge transfer resistance decreased with increasing lysozyme concentrations resulting from the positively charged protein. Xu et al. (2006) reported another strategy for the development of an impedimetric aptasensor. DNA aptamers were immobilized through a selfassembly process on a gold electrode. The specific interaction of thrombin with the sensor surface increased the electron
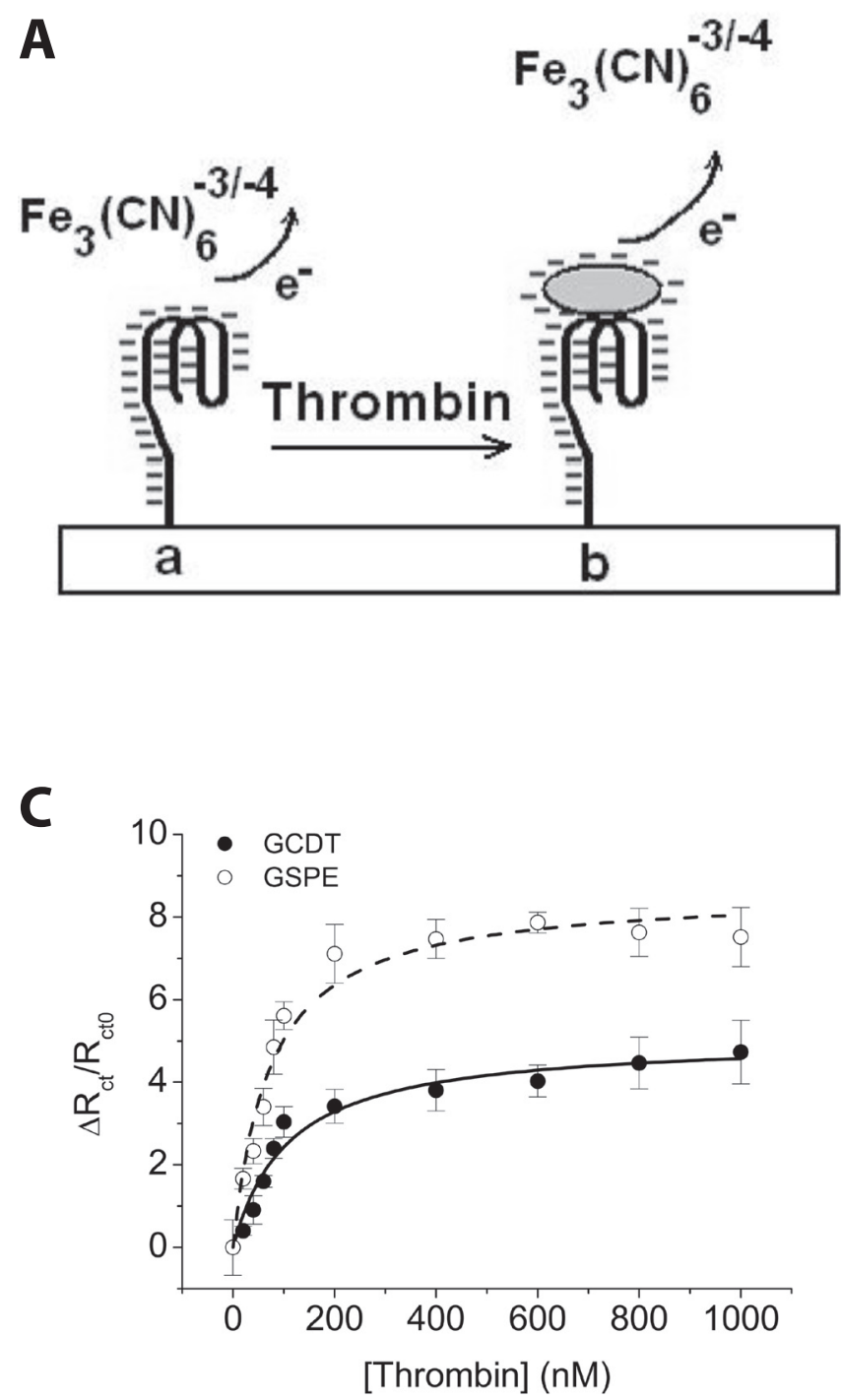

transfer resistance which was then amplified by means of guanidine hydrochloride in order to denature the captured thrombin. This increased the hydrated radius of thrombin and blocked electron transport to the electrode, and could detect thrombin with a sensitivity of $0.01 \mathrm{pM}$. A newer approach using pyrolyzed carbon as a support for immobilized DNA aptamers sensitive to thrombin has also been reported as a tool for the impedimetric detection of thrombin with a sensitivity of $0.5 \mathrm{nM}$ (Lee et al. 2008). EIS method for thrombin detection was also demonstrated in our recent paper in which aptamers were immobilized on fabricated gold electrodes based on compact discs (CD trodes) (GCDT) with a LOD of $5 \mathrm{nM}$. The sensitivity of detection was comparable with the aptasensor based on commercial gold screen-printed electrode (GSPE) (Fig. 9C) (Castillo et al. 2012).

The combination of perspective biosensing strategy and aptamers is based on the application of field effect transistors

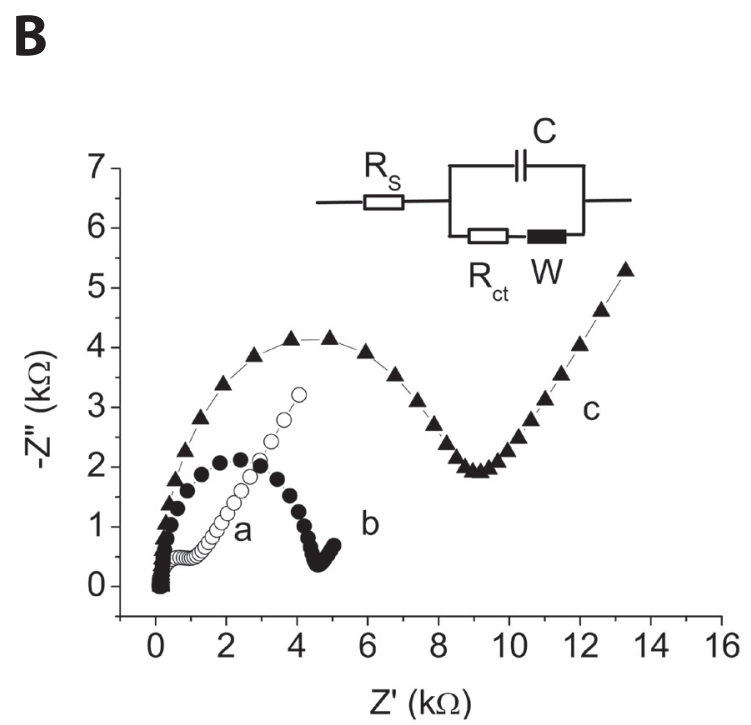

Figure 9. A. Schematic illustration of the electrochemical impedance spectroscopy (EIS) based detection of protein using a $\left[\mathrm{Fe}(\mathrm{CN})_{6}\right]^{-3 /-4}$ redox marker. Without the target protein the negatively-charged marker is repelled from the surface and its redox reaction is hindered (a). When the negatively charged protein binds to the aptamer probe, due to increased negative charge, further repealing of the redox marker takes place (b). B. Nyquist plot of fitted data for a bare gold (a), gold modified by TBA (b) and TBA-thrombin (c). Upper inset: The Randle's equivalent circuit used for fitting: electrolyte resistance RS, interfacial capacity $\mathrm{C}$, charge transfer resistance Rct, and Warburg impedance W. C. Plot of relative changes of charge transfer resistance, $\Delta \mathrm{R}_{\mathrm{ct}} / \mathrm{R}_{\mathrm{ct} 0}$, as a function of thrombin concentration obtained on CD disc (GCDT) and gold screen printed electrode (GSPE) based aptasensors, respectively. Dashed and solid lines indicate fitted results for GSPE and GCDT based sensors, respectively, according to Langmuir isotherm equation. Results represent mean \pm SD obtained at 5 independent measurements (according to Castillo et al. (2012) with permission of Wiley-VCH). 


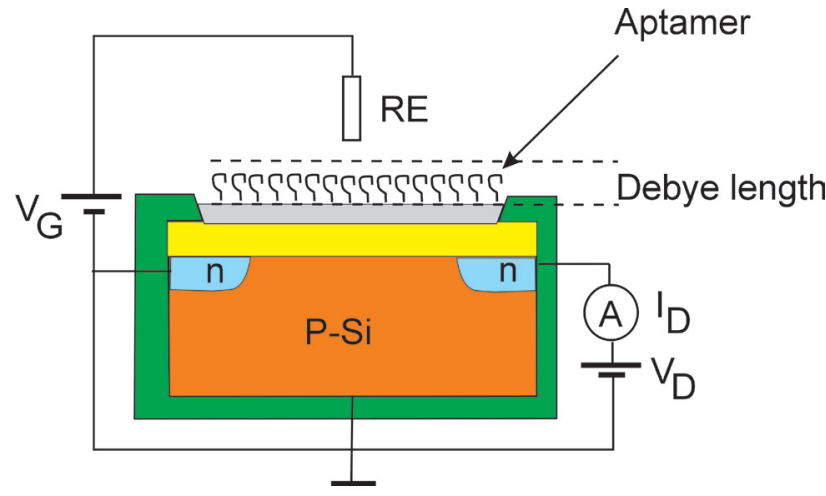

Figure 10. Schematic representation of aptasensor based on field effect transistor. Sensing layer composed of aptamers immobilised on the surface (ion-sensitive membrane, carbon nanotubes, graphene, etc) is localized on the insulating layer at the top of the p-type silicon. The electrical contact is provided by $n$-type silicon (for explanation see the text).

(FET), highly responsive microdevices which integrate sensing and transducing elements into one compact unit. The principles of FET and ISFET (Ion-Sensitive FET) operation have been outlined in a number of publications, for example Eggins (2004). Described briefly, the chemically sensitive surface of ISFET is in contact with analyte solution (Fig. 10). The processes which take place on the sensing surface usually affect the potential of the sensing layer, $\mathrm{V}_{\mathrm{T}}$, which in turn affects the value of the drain current $\mathrm{I}_{\mathrm{D}}$. The drain current is proportional to the difference $V_{G}-V_{T}-V_{R E}$, where $V_{G}$ is the gate voltage and $\mathrm{V}_{\mathrm{RE}}$ is the reference electrode potential. The drain current is therefore measured at constant $\mathrm{V}_{\mathrm{G}}$, or $\mathrm{V}_{\mathrm{G}}$ is measured at constant $\mathrm{I}_{\mathrm{D}}$. In order to sense the interaction on the FET surface it is important that the analyte interacts with the surface or surface covered by receptors in a framework based on so-called Debye lengths, which is approx. $3 \mathrm{~nm}$ for $10 \mathrm{mM}$ ionic concentrations. This rule is especially true for aptamers with dimensions of 1-2 nm; as the interaction of small molecules or proteins with aptamers on the surface of FET takes place in a layer with a thickness comparable to Debye length, the sensitivity of detection is high. The direct detection of thrombin using a single walled carbon nanotube field effect transistor (SWNT-FET) was reported by So et al. (2005). In this study, the aptamer was covalently immobilized on carbon nanotubes modified by Twin 20. The addition of thrombin resulted in a drop in the conductivity of the device. This could be explained by screening the negative charge of DNA due to presence of thrombin, which was positively charged at $\mathrm{pH} 5.4$ under experimental conditions. Certainly, the isoelectric point of thrombin is rather high: 7.0-7.6. The lowest LOD of the sensor was $10 \mathrm{nM}$. The sensor was selective to thrombin, as was proved by a subsequent experiment in which elastase was used in place of thrombin. Elastase is a serine protease with an isoelectric point and molecular weight similar to that of thrombin. The addition of elastase resulted in current changes which were considerably lower than those recorded with thrombin. It was possible to regenerate the sensor by removing the bound thrombin molecules using $6 \mathrm{M}$ of guanidine hydrochloride solution.

Potentiometry is an additional label-free detection technique which is used in biosensing applications, and our research adopted this method to develop a new procedure for thrombin detection (Evtugyn et al. 2008a). The sensor was created by electrochemically depositing polymeric phenothiazine dyes $\mathrm{MB}$ and methylene green (MG) onto a glass carbon electrode and then applying double stranded DNA (dsDNA) as a target for antibodies (DNA sensor) or DNA aptamers specific to human $\alpha$-thrombin (aptasensor). The biosensors were incubated first at $\mathrm{pH} 7.5$ and then at $\mathrm{pH} 3.0$ and the difference in potentials, $\Delta \mathrm{E}$, was used as a measure of protein concentration. The potentiometric DNA-sensors were tested in a standard serum of autoimmune disease patients (systemic lupus erythemathosus (SLE) and autoimmune thyroidites). It was shown that the $\triangle \mathrm{E}$ value of DNA-sensor is dependent on the dilution of serum in the range of 1:1 to $1: 100$. Non-thermostated serum exhibited a bell-shape dependence of $\Delta \mathrm{E}$ on serum dilution due to the interfering effect of serine proteins at a maximum dilution of between 1:20 and 1:50. In the case of SLE serum thermostated at $56^{\circ} \mathrm{C}$, the $\Delta \mathrm{E}$ showed a linear decrease as a function of serum dilution and reached saturation at dilution 1:20. Similarly the changes in the potential of aptasensor allowed us to determine thrombin in the range of $1 \mathrm{nM}$ to $1 \mu \mathrm{M}$. These potentiometric biosensors demonstrate a sensitivity which is comparable to that of traditional methods, and could be used for preliminary diagnosis of autoimmune diseases and thrombin. The developed method is, however, simpler and cheaper in comparison with most commonly used methods.

Mass detection using the quartz crystal microbalance (QCM) method has proven to be very useful in the development of aptasensors (Bini et al. 2007). The principle of QCM is based on immobilization of the aptamers or other receptors on the gold electrodes sputtered at the AT-cut quartz crystal. The resonant frequency (typically 5-10 MHz) of the crystal oscillations is sensitive to the thickness or mass of the sensing layer. According to Sauerbrey, the increase of the layer mass on the top of the crystal resulted in decrease of the resonant frequency that can be used as an analytical signal (Sauerbrey 1959) (Fig. 11). In the solution, however, also the viscosity affects the resonant frequency. This should be taken into account in a more detailed study of affinity interactions at surfaces using QCM (Ellis and Thompson 2004). Moreover, the existence of aptamers sensitive to fibrinogen and heparin binding sites is of great advantage in sensing strategies using QCM. This has been demonstrated 


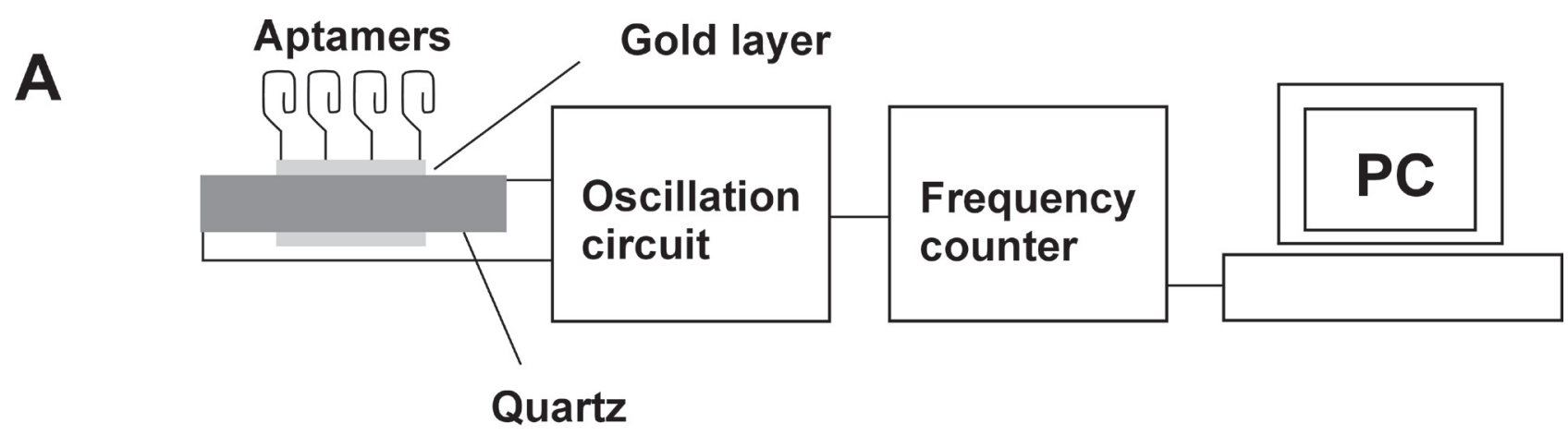

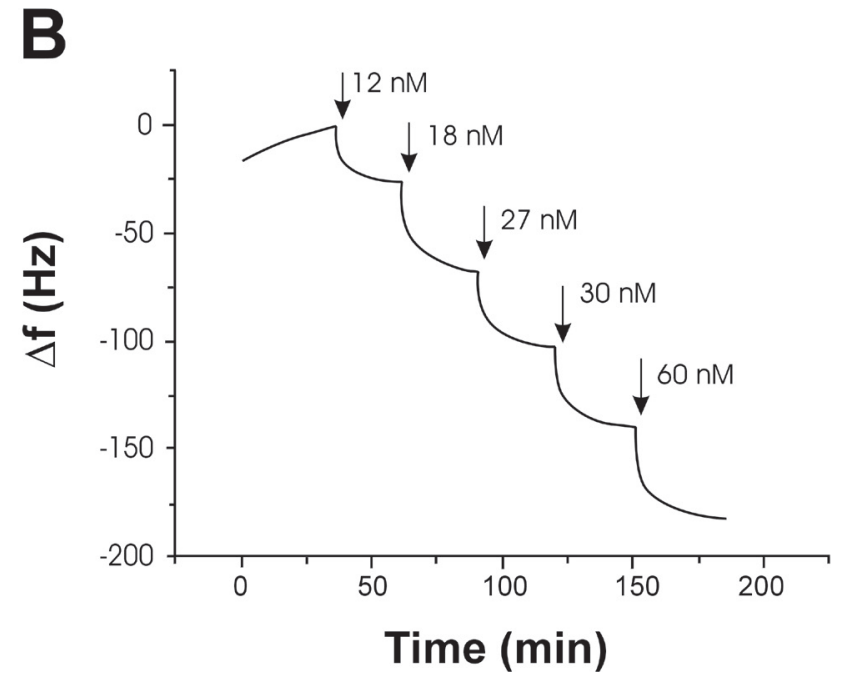

by Pavlov et al. (2004) who used an aptamer modified with gold nanoparticles for detection amplification; this complex was then bound to thrombin which had previously been bound to a surface modified by another thrombin-sensitive aptamer. Catalytic enlargement of the nanoparticles resulted in a 90 fold amplification of signal, allowing the detection of sub nM concentrations of thrombin. Electrochemical quartz crystal microbalance (EQCM), the combination of QCM with electrochemical measurements, has also been shown to be very effective. We applied EQCM to thrombin specific aptasensors based on MWCNTs-MB (multi-walled carbon nanotubes-methylene blue) composite (Evtugyn et al. 2008b) (Fig. 12A). Fluctuations in the oscillation frequency of the quartz crystal which reflect both mass and viscosity changes at the crystal surface were measured during cycling of the voltage in the range of -0.7 to $+0.6 \mathrm{~V}$ (vs. Ag/ $\mathrm{AgCl}$ reference electrode) a process which aided the interaction between thrombin and the DNA aptamers. This method has substantially improved the thrombin detection limit; while conventional QCM methods with aptamers immobilized by avidin-biotin technology resulted in thrombin detection
Figure 11. A. Schematic representation of QCM biosensor. The sensing layer is formed at one site of the AT-cut quartz crystal at the sputtered gold layer. The oscillation of the crystal is initiated by external oscillation circuit and the frequency is measured by frequency counter. B. The kinetics of the frequency changes of the crystal with immobilised TBA aptamers following addition of thrombin at various concentrations.

with a LOD of $10 \mathrm{nM}$ (Hianik et al. 2005), the immobilization of aptamers on the MWCNTs-MB composite layer and simultaneous cycling of the voltage resulted in a LOD of $0.3 \mathrm{nM}$ (Evtugyn et al. 2008b; Hianik et al. 2008). In our work (Hianik et al. 2008) we showed higher sensitivity of aptasensor based on aptamer dimers (aptabodies) in comparison to the conventional single-stranded aptamers (Fig. 12). Other approaches for thrombin detection have recently been reviewed in a paper by Tucker et al. (2012), and a novel approach for the optical detection of thrombin by multiplexed aptasensors using functionalized graphene oxide and logic gate operations have recently been reported by Liu et al. (2012).

\section{Conclusion}

The high significance of G-quadruplexes and their role in cancer diseases and in the molecular recognition of various targets suggests that they will become the subject of increased academic interest in the foreseeable future, with particular 


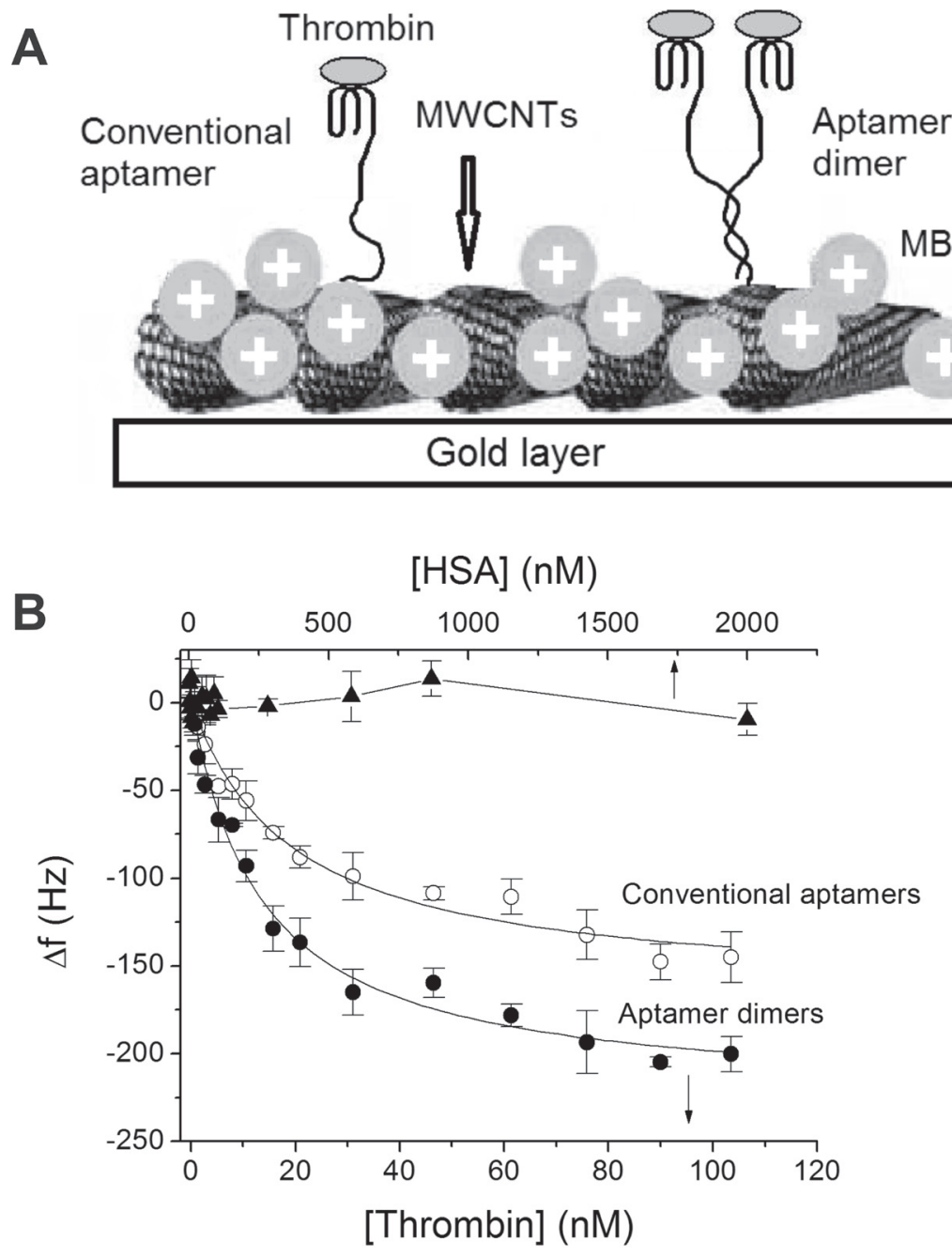

Figure 12. A. Scheme of the aptasensor based on multiwalled carbon nanotubes (MWCNTs) and methylene blue (MB) composites with immobilised aptamers of two configurations: conventional single stranded aptamers and aptamer dimmer (aptabody). B. The plot of frequency changes $v s$. concentration of the thrombin for the EQCM biosensor presented at A. for conventional aptamers and aptamer dimers. Addition of human serum albumin (HSA) to the sensing surface composed either by conventional aptamers or aptamer dimers did not change frequency significantly (full triangles). (According to $\mathrm{Hi}$ anik et al. (2008), with permission of Bentham Science Publishers Ltd.). focus being placed on their polymorphism and on the mechanism of their interaction with various molecules. DNA and RNA aptamers containing quadruplexes are also the focus of research which aims to develop them as a potential replacement for antibodies, and their development as biosensors is also of considerable interest. However, with the exception of the widely-studied thrombin-binding aptamer, our knowledge of the mechanisms which govern the binding of proteins and small molecules to aptamers is still relatively limited. The joint efforts of experimental and computational approaches could help in understanding these phenomena including the binding of cancer therapeutics to G-quadruplexes.

Acknowledgements. This study was supported by grants from the Slovak Grant Agency (1/0785/12 to T.H and 1/0504/12 to V.V.), Slovak Research and Development Agency (APVV-0410-10 to T.H. and APVV-0280-11 to V.V.), European Cooperation in Science and Technology (COST MP802 and TD1003), IRSES 7 FP program of EU, Materials Enhancement for Technological Applications
(META), grant agreement No. 269182 and by Centre of Excellence SAS for Functionalized Multiphase Materials (FUN-MAT).

\section{References}

Adrian M., Heddi B., Phan A. T. (2012): NMR spectroscopy of Gquadruplexes. Methods Enzymol. 338, 341-371

Allali-Hassani A., Pereira M. P., Navani N. K., Brown E. D., Li Y. F. (2007): Isolation of DNA aptamers for CDP-ribitol synthase, and characterization of their inhibitory and structural properties. ChemBioChem 8, 2052-2057 http://dx.doi.org/10.1002/cbic.200700257

Ambrus A., Chen D., Dai J., Jones R. A., Yang D. (2005): Solution structure of the biologically relevant G-quadruplex element in the human c-myc promoter. Implications for G-quadruplex stabilization. Biochemistry 44, 2048-2058 http://dx.doi.org/10.1021/bi048242p

Andreola M. L., Pileur F., Calmels C., Ventura M., Tarrago-Litvak L., Toulme J. J., Litvak S. (2001): DNA aptamers selected against the 
HIV-1 RNase H display in vitro antiviral activity. Biochemistry 40, 10087-10094 http://dx.doi.org/10.1021/bi0108599

Avi-ó A., Mazzini S., Ferreira R., Gargallo R., Marquez V. E., Eritja R. (2012): The effect on quadruplex stability of North-nucleoside derivatives in the loops of the thrombin-binding aptamer. Bioorg. Med. Chem. 20, 4186-4193 http://dx.doi.org/10.1016/j.bmc.2012.06.005

Bang G. S., Cho S., Kim B. G. (2005): A novel electrochemical detection method for aptamer biosensors. Biosens. Bioelectr. 21, 863-870 http://dx.doi.org/10.1016/j.bios.2005.02.002

Bang I. (1910): Untersuchungen uber die Guanylsaure. Biochemische Zeitschrift, 26, 293-311

Bates P. J., Choi E. W., Nayak L. V. (2009): G-rich oligonucleotides for cancer treatment. Methods Mol. Biol. 542, 379-392 http://dx.doi.org/10.1007/978-1-59745-561-9_21

Becker R. C., Povsic T., Cohen M. G., Rusconi C. P., Sullenger B. (2010): Nucleic acid aptamers as antithrombotic agents: Opportunities in extracellular therapeutics. Thromb. Haemost. 103, 586-595 http://dx.doi.org/10.1160/TH09-10-0716

Berliner L. J. (1992): Thrombin: Structure and Function, Plenum Press, New York

Bini A., Minunni M., Tombelli S., Centi S., Mascini M. (2007): Analytical performances of aptamer-based sensing for thrombin detection. Anal. Chem. 79, 3016-3019 http://dx.doi.org/10.1021/ac070096g

Bock L. C., Griffin L. C., Latham J. A., Vermaas E. H., Toole J. J. (1992): Selection of single-stranded DNA molecules that bind and inhibit human thrombin. Nature 355, 564-566 http://dx.doi.org/10.1038/355564a0

Boon E. M., Ceres D. M., Drummond T. G., Hill M. G., Barton J. K. (2000): Mutation detection by electrocatalysis at DNA-modified electrodes. Nat. Biotechnol. 18, 1096-1100 http://dx.doi.org/10.1038/80301

Bugaut A., Balasubramanian S. (2012): Survey and summary. 5'UTR RNA G-quaduplexes: translation regulation and targeting. Nucleic Acids Res. 40, 4727-4741 http://dx.doi.org/10.1093/nar/gks068

Bunka D. H., Platonova O., Stockley P. G. (2010): Development of aptamer therapeutics. Curr. Opin. Pharmacol. 10, 557-562 http://dx.doi.org/10.1016/j.coph.2010.06.009

Cai W., Fan Y., Jiang Z., Yao J. (2010): A highly sensitive and selective resonance scattering spectral assay for potassium ion based on aptamer and nanosilver aggregation reactions. Talanta $\mathbf{8 1}$, $1810-1815$

http://dx.doi.org/10.1016/j.talanta.2010.03.046

Castillo G., Trnkova L., Hrdy R., Hianik T. (2012): Impedimetric aptasensor for thrombin recognition based on CD support. Electroanalysis 24, 1079-1087 http://dx.doi.org/10.1002/elan.201200041

Cerchia L., de Franciscis V. (2010): Targeting cancer cells with nucleic acid aptamers. Trends Biotechnol. 28, 517-525 http://dx.doi.org/10.1016/j.tibtech.2010.07.005

Chaires J. B. (2010): Human telomeric G-quadruplex, thermodynamic and kinetic studies of telomeric quadruplex stability. FEBS J. 277, 1098-1106 http://dx.doi.org/10.1111/j.1742-4658.2009.07462.x
Cheng A. K. H., Sen D., Yu H-Z. (2009): Design and testing of aptamer-based electrochemical biosensors for proteins and small molecules. Bioelectrochemistry 77, 1-12

http://dx.doi.org/10.1016/j.bioelechem.2009.04.007

Choi M. S., Yoon M., Baeg J. O., Kim J. (2009): Label-free dual assay of DNA sequences and potassium ions using an aptamer probe and a molecular light switch complex. Chem. Commun. 7419-7421 http://dx.doi.org/10.1039/b915994k

Chou S. H., Chin K. H., Wang A. H. (2005): DNA aptamers as potential anti-HIV agents. Trends Biochem. Sci. 30, 231-234 http://dx.doi.org/10.1016/j.tibs.2005.03.004

Coppola T., Varra M., Oliviero G., Galeone A., D’Isa G., Mayol L., Morelli E., Bucci M-R., Vellecco V., Cirino G., Borbone N. (2008): Synthesis, structural studies and biological properties of new TBA analogues containing an acyclic nucleotide. Bioorg. Med. Chem. 16, 8244-8253 http://dx.doi.org/10.1016/j.bmc.2008.07.040

Cruz-Aguado J. A., Penner G. (2008): Determination of ochratoxin a with a DNA aptamer. J. Agric. Food. Chem. 56, 10456-10461 http://dx.doi.org/10.1021/jf801957h

D’Atri V., Oliviero G., Amato J., Borbone N., D’Errico S., Mayol L., Piccialli V., Haider S., Hoorelbelke B., Balzarini J., Piccialli G. (2012): New anti-HIV aptamers based on tetra-end-linked DNA G-quadruplexes effect of the base sequence on anti-HIV activity. Chem. Commun. 48, 9516-9518

Dapic V., Bates P. J., Trent J. O., Rodger A., Thomas S. D., Miller D. M. (2002): Antiproliferative activity of G-quartet-forming oligonucleotides with backbone and sugar modifications. Biochemistry 41, 3676-3685 http://dx.doi.org/10.1021/bi0119520

Dapic V., Abdomerovic V., Marrington R., Peberdy J., Rodger A., Trent J. O., Bates P. J. (2003): Biophysical and biological properties of quadruplex oligodeoxyribonucleotides. Nucleic Acids Res. 31, 2097-2107 http://dx.doi.org/10.1093/nar/gkg316

De Soultrait V. R., Lozach P. Y., Altmeyer R., Tarrago-Litvak L., Litvak S., Andréola M. L. (2002): DNA aptamers derived from HIV-1 RNase $\mathrm{H}$ inhibitors are strong anti-integrase agents. J. Mol. Biol. 324, 195-203 http://dx.doi.org/10.1016/S0022-2836(02)01064-1

Do N. Q., Lim K. W., Teo M. H., Heddi B., Phan A. T. (2011): Stacking of G-quadruplexes: NMR structure of a G-rich oligonucleotide with potential anti-HIV and anticancer activity. Nucleic Acids Res. 39, 9448-9457 http://dx.doi.org/10.1093/nar/gkr539

Dovinova I., Hianik T. (1990): Calmodulin interaction with mesocaine-modified lipid bilayer. Gen. Physiol. Biophys. 9, $177-188$

Eggins B. R. (2004): Chemical sensors and biosensors. J. Wiley and Sons Ltd., Chichester

Ellington A. D., Szostak J. W. (1990): In vitro selection of RNA molecules that bind specific ligands. Nature 346, 818-822 http://dx.doi.org/10.1038/346818a0

Ellis J. S., Thompson M. (2004): Acoustic coupling at multiple interfaces and the liquid phase response of the thickness shearmode acoustic wave sensor. Chem. Commun. 1310-1311 http://dx.doi.org/10.1039/b402822h 
Evtugyn G. A., Porfireva A. V., Hianik T., Cheburova M. S., Budnikov H. C. (2008a): Potentiometric DNA sensor based on electropolymerized phenothiazines for protein detection. Electroanalysis 20, 1300-1308 http://dx.doi.org/10.1002/elan.200704186

Evtugyn G., Porfireva A., Ryabova M., Hianik T. (2008b): Aptasensor for thrombin based on carbon nanotubes-methylene blue composites. Electroanalysis 20, 2310-2316 http://dx.doi.org/10.1002/elan.200804345

Evtugyn G., Kostyleva V., Sitdikov R., Porfireva A., Savelieva M., Stoikov I., Antipin I., Hianik T. (2012): Electrochemical aptasensor based on a macrocyclic ligand bearing neutral red. Electroanalysis 24, 91-100 http://dx.doi.org/10.1002/elan.201100435

Farokhzad O. C., Jon S., Khademhosseini A., Tran T. N., LaVan D. A., Langer R. (2004): Nanoparticle-aptamer bioconjugates: A new approach for targeting prostate cancer cells. Cancer Res. 64, 7668-7672 http://dx.doi.org/10.1158/0008-5472.CAN-04-2550

Ferapontova E. E., Gothelf K. V. (2011): Recent advances in electrochemical aptamer-based sensors. Current Organic Chemistry 15, 498-505 http://dx.doi.org/10.2174/138527211794474483

Fialová M., Kypr J., Vorlícková M. (2006): The thrombin binding aptamer GGTTGGTGTGGTTGG forms a bimolecular guanine tetraplex. Biochem. Biophys. Res. Commun. 344, $50-54$ http://dx.doi.org/10.1016/j.bbrc.2006.03.144

Foy J. W. D., Rittenhouse K., Modi M., Patel M. (2007): Local tolerance and systemic safety of pegaptanib sodium in the dog and rabbit. J. Ocul. Pharmacol. Ther. 23, 452-466 http://dx.doi.org/10.1089/jop.2006.0149

Fry M., Loeb L. A. (1994): The fragile X syndrome d(CGG)n nucleotide repeats form a stable tetrahelical structure. Proc. Natl. Acad. Sci. USA 91, 4950-4954 http://dx.doi.org/10.1073/pnas.91.11.4950

Gatto B., Palumbo M., Sissi C. (2009): Nucleic acid aptamers based on the G-quadruplex structure: therapeutic and diagnostic potential. Curr. Med. Chem. 16, 1248-1265 http://dx.doi.org/10.2174/092986709787846640

Gellert M., Lipsett M. N., Davies D. R. (1962): Helix formation by guanylic acid. Proc. Natl Acad. Sci. U.S.A. 48, 2013-2018 http://dx.doi.org/10.1073/pnas.48.12.2013

Gragoudas E. S., Adamis A. P., Cunningham E. T., Jr., Feinsod, M., Guyer D. R. (2004): Pegaptanib for neovascular age-related macular degeneration. N. Engl. J. Med. 351, 2805-2816 http://dx.doi.org/10.1056/NEJMoa042760

Gray D. M., Wen J. D., Gray C. W., Repges R., Repges C., Raabe G., Fleischhauer J. (2008): Measured and calculated CD spectra of G-quartets stacked with the same or opposite polarities. Chirality 20, 431-440 http://dx.doi.org/10.1002/chir.20455

Gray R. D., Chaires J. B. (2011): Analysis of multidimensional Gquadruplex melting curves. Curr. Prot. Nucleic Acid Chem. 45, 17.4.1-17.4.16

Green L. S., Jellinek D., Jenison R., Ostman A., Heldin C. H., Janjic N. (1996): Inhibitory DNA ligands to platelet-derived growth factor B-chain. Biochemistry 35, 14413-14424 http://dx.doi.org/10.1021/bi961544+

Guo Q., Lu M., Kallenbach N. R. (1992): Adenine affects the structure and stability of telomeric sequence. J. Biol. Chem. 267, 15293-15300

Haq I., Chowdhry B. Z., Chaires J. B. (1997): Singular value decomposition of 3-D DNA melting curves reveals complexity in the melting process. Eur. Biophys. J. 26, 419-426 http://dx.doi.org/10.1007/s002490050096

Hardin C. C., Perry A. G., White K. (2000): Thermodynamic and kinetic characterization of the dissociation and assembly of quadruplex nucleic acids. Biopolymers 56, 147-194 http://dx.doi.org/10.1002/1097-0282(2000/2001)56:3<147:: AID-BIP10011>3.0.CO;2-N

Hasegawa H., Taira K-I., Sode K., Ikebukuro K. (2008): Improvement of aptamer affinity by dimerization. Sensors $\mathbf{8}$, 1090-1098

http://dx.doi.org/10.3390/s8021090

Hianik T., Ostatna V., Zajacova Z., Stoikova E., Evtugyn G. (2005): Detection of aptamer-protein interactions using QCM and electrochemical indicator methods. Bioorg. Med. Chem. Lett. 15, 291-295 http://dx.doi.org/10.1016/j.bmcl.2004.10.083

Hianik T., Porfireva A., Grman I., Evtugyn G. (2008): Aptabodies - new type of artificial receptors for detection proteins. Protein Pept. Lett. 15, 799-805 http://dx.doi.org/10.2174/092986608785203656

Hianik T., Wang J. (2009): Electrochemical aptasensors - recent achievements and perspectives. Electroanalysis 21, 1223-1235 http://dx.doi.org/10.1002/elan.200904566

Hianik T., Grman I., Karpisova I. (2009): The effect of DNA aptamer configuration on the sensitivity of detection thrombin at surface by acoustic method. Chem. Commun. 41, 6303-6306 http://dx.doi.org/10.1039/b910981a

Hirao I., Madin K. Endo Y., Yokoyama S., Ellington A. D. (2000): RNA aptamers that bind to and inhibit the ribosome-inactivating protein, pepocin. J. Biol. Chem. 275, 4943-4948 http://dx.doi.org/10.1074/jbc.275.7.4943

Hong E. S., Yoon H. J., Kim B., Yim Y. H., So H. Y., Shin S. K. (2010): Mass spectrometric studies of alkali metal ion binding on thrombin binding aptamer DNA. J. Am. Soc. Mass Spectrom. 21, 1245-1255 http://dx.doi.org/10.1016/j.jasms.2010.03.035

Hotoda H., Koizumi M., Koga R., Kaneko M., Momota K., Ohmine T., Furukawa H., Agatsuma T., Nishigaki T., Sone J., Tsutsumi S., Kosaka T., Abe K., Kimura S., Shimada K. (1998): Biologically active oligodeoxyribonucleotides. 5. 5'-End-substituted $\mathrm{d}$ (TGGGAG) possesses anti-human immunodeficiency virus type 1 activity by forming a G-quadruplex structure. J. Med. Chem. 41, 3655-3663 http://dx.doi.org/10.1021/jm970658w

Hu J., Wu J., Li C, Zhu L., Zhang W. Y., Kong G., Lu Z., Yang C. J. (2011): A G-quadruplex aptamer inhibits the phosphatase activity of oncogenic protein Shp2 in vitro. Chembiochem 12, 424-430 http://dx.doi.org/10.1002/cbic.201000470

Huizenga D. E., Szostak J. W. (1995): A DNA aptamer that binds adenosine and ATP. Biochemistry 34, 656-665 
http://dx.doi.org/10.1021/bi00002a033

Ikebukuro K., Kiyohara C., Sode K. (2005): Novel electrochemical sensor system for protein using the aptamers in sandwich manner. Biosens. Bioelectron. 20, 2168-2172 http://dx.doi.org/10.1016/j.bios.2004.09.002

Jayasena S. D. (1999): Aptamers: an emerging class of molecules that rival antibodies in diagnostics. Clin. Chem. 45, $1628-1650$

Jing N., Marchand C., Liu J., Mitra R., Hogan M. E., Pommier Y. (2000): Mechanism of inhibition of HIV-1 integrase by G tetrad- forming oligonucleotides in vitro. J. Biol. Chem. 275, $21460-21467$ http://dx.doi.org/10.1074/jbc.M001436200

Jing N., Hogan M. E. (1998): Structure-activity of tetrad-forming oligonucleotides as a potent anti-HIV therapeutic drug. J. Biol. Chem. 273, 34992-34999 http://dx.doi.org/10.1074/jbc.273.52.34992

Jones L. A., Clancy L. E., Rawlinson W. D., White P. A. (2006): Highaffinity aptamers to subtype 3 a hepatitis $\mathrm{C}$ virus polymerase display genotypic specificity. Antimicrob. Agents Chemother. 50, 3019-3027 http://dx.doi.org/10.1128/AAC.01603-05

Kang, Y., Feng K-J., Chen J-W., Jiang J-H., Shen G-L., Yu R-Q. (2008): Electrochemical detection of thrombin by sandwich approach using antibody and aptamer. Bioelectrochemistry 73, 76-81 http://dx.doi.org/10.1016/j.bioelechem.2008.04.024

Kankia B. I., Marky L. A. (2001): Folding of the thrombin aptamer into a G-quadruplex with Sr2+: stability, heat, and hydration. J. Am. Chem. Soc. 123, 10799-10804 http://dx.doi.org/10.1021/ja010008o

Kankia B. I., Barany G., Musier-Forsyth K. (2005): Unfolding of DNA quadruplexes induced by HIV-1 nucleocapsid protein. Nucleic Acids Res. 33, 4395-4403 http://dx.doi.org/10.1093/nar/gki741

Keefe A. D., Cload S. T. (2008): SELEX with modified nucleotides. Curr. Opin. Chem. Biol. 12, 448-456 http://dx.doi.org/10.1016/j.cbpa.2008.06.028

Keefe A. D., Pai S., Ellington A. (2010): Aptamers as therapeutics. Nat. Rev. Drug. Discov. 9, 537-550 http://dx.doi.org/10.1038/nrd3141

Lamberti I., Rakitka J., Hianik T., Mosiello L. (2011): A piezoelectric quartz crystal sensor applied for thrombin-binding aptamers. In: Sensors and Microsystems. Lecture Notes in Electrical Engineering (Eds. G. Neri, N. Donato, A. d'Amico', C. Di Natale), Vol. 91, pp. 449-453, Springer Science + Business Media B.V.

Lee J. A., Hwang S., Kwak J., Park S., Lee S. S., Lee K. C. (2008): An electrochemical impedance biosensor with aptamer-modified pyrolyzed carbon electrode for label-free protein detection. Sens. Actuators B, 129, 372-379 http://dx.doi.org/10.1016/j.snb.2007.08.034

Lee I-H., An S., Yu M. K., Kwon H-K., Im S-H., Jon S. (2011): Targeted chemoimmunotherapy using drug-loaded aptamer-dendrimer bioconjugates. J. Controlled Rel. 155, 435-441 http://dx.doi.org/10.1016/j.jconrel.2011.05.025

Li Y., Geyer C. R., Sen D. (1996): Recognition of anionic porphyrins by DNA aptamers. Biochemistry 35, 6911-6922 http://dx.doi.org/10.1021/bi960038h
Li R., Xiong C., Xiao Z., Ling L. (2012): Colorimetric detection of cholesterol with G-quadruplex-based DNAzymes and ABTS2. Anal. Chim. Acta 724, 80-85 http://dx.doi.org/10.1016/j.aca.2012.02.015

Li T., Wang E., Dong S. (2010): Lead (II)-induced allosteric G-quadruplex DNAzyme as a colorimetric and chemiluminescence sensor for highly sensitive and selective $\mathrm{Pb} 2+$ detection. Anal. Chem. 82, 1515-1520 http://dx.doi.org/10.1021/ac902638v

Lim K. W., Amrane S., Bouaziz S., Xu W., Mu Y., Patel D. J., Luu K. N., Phan A. T. (2009): Structure of the human telomere in $\mathrm{K}+$ solution: a stable basket-type G-quadruplex with only two G-tetrad layers. J. Am. Chem. Soc. 131, 4301-4309 http://dx.doi.org/10.1021/ja807503g

Liu C. W., Huang C. C., Chang H. T. (2009): Highly selective DNAbased sensor for lead (II) and mercury (II) ions. Anal. Chem. 81, 2383-2387 http://dx.doi.org/10.1021/ac8022185

Liu X., Ruth Aizen R., Ronit Freeman R., Omer Yehezkeli O., Willner I. (2012): Multiplexed aptasensors and amplified DNA sensors using functionalized graphene oxide. Application for logic gate operations. ACS Nano 6, 3553-3563 http://dx.doi.org/10.1021/nn300598q

Lv L., Guo Z., Wang J., Wang E. (2012): G-quadruplex as signal transducer for biorecognition events. Current Pharmaceutical Design, 18, 2076-2095 http://dx.doi.org/10.2174/138161212799958459

Macaya R. F., Schultze P., Smith F. W., Roe J. A., Feigon J. (1993): Thrombin-binding DNA aptamer forms a unimolecular quadruplex structure in solution. Proc. Natl. Acad. Sci. U.S.A. 90, 3745-3749 http://dx.doi.org/10.1073/pnas.90.8.3745

Mairal T., Özalp V. C., Sánchez P. L., Mir M., Katakis I., O’Sullivan C. K. (2008): Aptamers: molecular tools for analytical applications. Anal. Bioanal. Chem. 390, 989-1007 http://dx.doi.org/10.1007/s00216-007-1346-4

Marathias V. M., Bolton P. H. (2000): Structures of the potassiumsaturated, 2:1, and intermediate, 1:1, forms of a quadruplex DNA. Nucleic Acids Res. 28, 1969-1977 http://dx.doi.org/10.1093/nar/28.9.1969

Marky L. A., Breslauer K. J. (1987): Calculating thermodynamic data for transitions of any molecularity from equilibrium melting curves. Biopolymers 26, 1602-1620 http://dx.doi.org/10.1002/bip.360260911

Masiero S., Trotta R., Pieraccini S., De Tito S., Perone R., Randazzo A., Spada G. P. (2010): A non-empirical chromophoric interpretation of CD spectra of DNA G-quadruplex structures. Org. Biomol. Chem. 8, 2683-2692 http://dx.doi.org/10.1039/c003428b

Marusic M., Sket P., Bauer L., Viglasky V., Plavec J. (2012): Solutionstate structure of an intramolecular G-quadruplex with propeller, diagonal and edgewise loops. Nucleic Acids Res. 40, 6946-6956 http://dx.doi.org/10.1093/nar/gks329

Mergny J-L., Phan A-T., Lacroix L. (1998): Following G-quartet formation by UV-spectroscopy. FEBS Lett. 435, 74-78 http://dx.doi.org/10.1016/S0014-5793(98)01043-6

Michalowski D., Chitima-Matsiga R., Held D. M., Burke D. H. (2008): Novel bimodular DNA aptamers with guanosine 
quadruplexes inhibit phylogenetically diverse HIV-1 reverse transcriptases. Nucleic Acids Res. 36, 7124-7135 http://dx.doi.org/10.1093/nar/gkn891

Mir M., Vreeke M., Katakis I. (2006): Different strategies to develop an electrochemical thrombin aptasensor. Electrochem. Commun. 8, 505-511 http://dx.doi.org/10.1016/j.elecom.2005.12.022

Mondragon-Sanchez J. A., Santamaria R., Garduno-Juarez R. (2011): Docking on the DNA G-quadruplex: A molecular electrostatic potential study. Biopolymers 95, 641-650 http://dx.doi.org/10.1002/bip.21634

Moyzis R. K., Buckingham J. M., Cram L. S., Dani M., Deaven L. L., Jones M. D., Meyne J., Ratliff R. L., Wu J. R. (1988): A highly conserved repetitive DNA sequence, (TTAGGG)n, present at the telomeres of human chromosomes. Proc. Natl Acad. Sci. U.S.A. 85, 6622-6626 http://dx.doi.org/10.1073/pnas.85.18.6622

Mukundan V. T., Do N. Q., Phan A. T. (2011): HIV-1 integrase inhibitor T30177 forms a stacked dimeric G-quadruplex structure containing bulges. Nucleic Acids Res. 39, 8984-8991 http://dx.doi.org/10.1093/nar/gkr540

Nagatoishi S., Tanaka Y., Tsumoto K. (2007): Circular dichroism spectra demonstrate formation of the thrombin-binding DNA aptamer G-quadruplex under stabilizing-cation-deficient conditions. Biochem. Biophys. Res. Commun. 352, 812-817 http://dx.doi.org/10.1016/j.bbrc.2006.11.088

Neidle S., Parkinson, G. N. (2003): The structure of telomeric DNA. Curr. Opin. Struct. Biol. 13, 275-283 http://dx.doi.org/10.1016/S0959-440X(03)00072-1

Neundlinger I., Poturnayova A., Karpisova I., Rankl C., Hinterdorfer P., Snejdarkova M., Hianik T., Ebner A. (2011). Characterization of enhanced monovalent and bivalent thrombin DNA aptamer binding using single molecule force spectroscopy. Biophys. J. 101, 1781-1787 http://dx.doi.org/10.1016/j.bpj.2011.07.054

Ni X., Castanares M., Mukherjee A., Lupold S. E. (2011): Nucleic acid aptamers: clinical applications and promising new horizons. Curr. Med. Chem. 18, 4206-4214 http://dx.doi.org/10.2174/092986711797189600

Noma T., Sode K., Ikebukuro K. (2006): Characterization and application of aptamers for Taq DNA polymerase selected using an evolution-mimicking algorithm. Biotechnol. Lett. 28, 1939-1944 http://dx.doi.org/10.1007/s10529-006-9178-4

Nonaka Y., Sode K., Ikebukuro K. (2010): Screening and improvement of an anti-VEGF DNA aptamer. Molecules 15, 215-225 http://dx.doi.org/10.3390/molecules15010215

Ogasawara D., Hachiya N. S., Kaneko K., Sode K., Ikebukuro K. (2009): Detection system based on the conformational change in an aptamer and its application to simple bound/free separation. Biosens. Bioelectron. 24, 1372-1376 http://dx.doi.org/10.1016/j.bios.2008.07.082

Okazawa A., Maeda H., Fukusaki E., Katakura Y., Kobayashi A. (2000): In vitro selection of hematoporphyrin binding DNA aptamers. Bioorg. Med. Chem. Lett. 10, 2653-2656
http://dx.doi.org/10.1016/S0960-894X(00)00540-0

Ohsen C. M., Lee H-T., Marky L.A. (2009): Unfolding thermodynamics of intramolecular G-quadruplex: base sequence contribution of the loops. J. Phys. Chem. B 113, $2587-2595$ http://dx.doi.org/10.1021/jp806853n

Oliviero G., Amato J., Borbone N., D’Errico S., Galeone A., Mayol L., Haider S., Olubiyi O., Hoorelbeke B., Balzarini J., Piccialli G. (2010): Tetra-end-linked oligonucleotides forming DNA G-quadruplexes: a new class of aptamers showing anti-HIV activity. Chem. Commun. 46, 8971-8973 http://dx.doi.org/10.1039/c0cc02866e

Orava E. W., Cicmil N., Gariépy J. (2010): Delivering cargoes into cancer cells using DNA aptamers targeting internalized surface portals. Biochim. Biophys. Acta 1798, 2190-2200 http://dx.doi.org/10.1016/j.bbamem.2010.02.004

Orava E. W., Jarvik N., Shek Y. L., Sidhu S. S., Garipy J. (2013): A short DNA aptamer that recognizes TNF-alpha and blocks its activity in vitro. ACS Chem. Biol. 8, 170-178 http://dx.doi.org/10.1021/cb3003557

Padmanabhan K., Padmanabhan K. P., Ferrara J. D., Sadler J. E., Tulinsky A. (1993): The structure of a-thrombin inhibited by a 15-mer single-stranded DNA aptamer. J. Biol. Chem. 268, 17651-17654

Paeschke K., Simonsson T., Postberg J., Rhodes D., Lipps H. (2005): J. Nat. Struct. Mol. Biol. 12, 847-854 http://dx.doi.org/10.1038/nsmb982

Parkinson G. N., Lee M. P., Neidle S. (2002): Crystal structure of parallel quadruplexes from human telomeric DNA. Nature 417, 876-880 http://dx.doi.org/10.1038/nature755

Pavlov V., Xiao Y., Shlyahovsky B., Willner I. (2004): Aptamer-functionalized Au nanoparticles for the amplified optical detection of thrombin. J. Am. Chem. Soc. 126, 11768-11769 http://dx.doi.org/10.1021/ja046970u

Phillips J. A., Lopez-Colon D., Zhu Z., Xu Y., Tan W. (2008): Applications of aptamers in cancer cell biology. Anal. Chim. Acta 621, 101-108 http://dx.doi.org/10.1016/j.aca.2008.05.031

Pileur F., Andreola M. L., Dausse E., Michel J., Moreau S., Yamada H., Gaidamakov S. A., Crouch R. J., Toulmé J-J., Cazenave C. (2003): Selective inhibitory DNA aptamers of the human RNase H1. Nucleic Acids Res. 31, 5776-5788 http://dx.doi.org/10.1093/nar/gkg748

Ponikova S., Antalik M., Hianik T. (2008): A circular dichroism study of the stability of guanine quadruplexes of thrombin DNA aptamers at presence of $\mathrm{K}+$ and $\mathrm{Na}+$ ions. Gen. Physiol. Biophys. 27, 271-277

Poniková S., Tlučková K., Antalík M., Víglaský V., Hianik T. (2011): The circular dichroism and differential scanning calorimetry study of the properties of DNA aptamer dimers. Biophys. Chem. 155, 29-35 http://dx.doi.org/10.1016/j.bpc.2011.02.004

Potty A. S., Kourentzi K., Fang H., Jackson G. W., Zhang X., Legge G. B., Willson R. C. (2009): Biophysical characterization of DNA aptamer interactions with vascular endothelial growth factor. Biopolymers 91,145-156 http://dx.doi.org/10.1002/bip.21097 
Radi A. E., Acero Sanchez J. L., Baldrich E., O’Sullivan C. K. (2006): Reagentless, reusable, ultrasensitive electrochemical molecular beacon aptasensor. J. Am. Chem. Soc. 128, $117-124$ http://dx.doi.org/10.1021/ja053121d

Renciuk D., Kejnovská I., Skoláková P., Bednárová K., Motlová J., Vorlíčková M. (2009): Arrangements of human telomere DNA quadruplex in physiologically relevant $\mathrm{K}+$ solutions. Nucleic Acids Res. 37, 6625-6634 http://dx.doi.org/10.1093/nar/gkp701

Reyes-Reyes E. M., Teng Y., Bates P. J. (2010): A new paradigm for aptamer therapeutic AS1411 action: uptake by macropinocytosis and its stimulation by a nucleolin-dependent mechanism. Cancer Res. 70, 8617-8629 http://dx.doi.org/10.1158/0008-5472.CAN-10-0920

Ristano A., Fox K. R. (2003): Stability of intramolecular DNA quadruplexes: comparison with DNA duplexes. Biochemistry 42, 6507-6513 http://dx.doi.org/10.1021/bi026997v

Robertson D. L., Joyce G. F. (1990): Selection in vitro of an RNA enzyme that specifically cleaves single-stranded DNA. Nature, 344, 467-468 http://dx.doi.org/10.1038/344467a0

Rodriguez M. C., Kawde A-N., Wang J. (2005): Aptamer biosensor for label-free impedance spectroscopy detection of proteins on recognition-induced switching of the surface charge. Chem. Commun. 4267-4269 http://dx.doi.org/10.1039/b506571b

Ruckman J., Green L. S., Beeson J., Waugh S., Gillette W. L., Henninger D. D., Claesson- Welsh L., Janjic N. (1998): 2'-Fluoropyrimidine RNA-based aptamers to the 165-amino acid form of vascular endothelial growth factor (VEGF165). Inhibition of receptor binding and VEGF-induced vascular permeability through interactions requiring the exon 7 -encoded domain. J. Biol. Chem. 273, 20556-20567

Russo Krauss I., Merlino A., Giancola C., Randazzo A., Mazzarella L., Sica F. (2011): Thrombin-aptamer recognition: a revealed ambiguity. Nucleic Acids Res. 39, 7858-7867 http://dx.doi.org/10.1093/nar/gkr522

Russo Krauss I., Merlino A., Randazzo A., Novellino E., Mazzarella L., Sica F. (2012): High-resolution structures of two complexes between thrombin and thrombin-binding aptamer shed light on the role of cations in the aptamer inhibitory activity. Nucleic Acids Res. 40, 8119-8128 http://dx.doi.org/10.1093/nar/gks512

Sauerbrey G. (1959): The use of oscillator for weighing thin layers and for microweighing, Z. Phys. 155, 206-210 http://dx.doi.org/10.1007/BF01337937

Scheller F. W., Wollenberg U., Warsinke A., Lisdat F. (2001): Research and development in biosensors. Curr. Opin. Biotechnol. 12, 35-40 http://dx.doi.org/10.1016/S0958-1669(00)00169-5

Schultze P., Hud N. V., Smith F. W., Feigon J. (1999): The effect of sodium, potassium and ammonium ions on the conformation of the dimeric quadruplex formed by the Oxytricha nova telomere repeat oligonucleotide d(G(4)T(4)G(4)). Nucleic Acids Res. 27, 3018-3028 http://dx.doi.org/10.1093/nar/27.15.3018
Shevchenko Y., Francis T. J., Blair D. A., Walsh R., DeRosa M. C., Albert, J. (2011): In situ biosensing with a surface plasmon resonance fiber grating aptasensor. Anal. Chem. 83, 7027-7034 http://dx.doi.org/10.1021/ac201641n

Shi Y., Huang W. T., Luo H. Q., Li N. B. (2011): A label-free DNA reduced graphene oxide-based fluorescent sensor for highly sensitive and selective detection of hemin. Chem. Commun. 47, 4676-4678 http://dx.doi.org/10.1039/c0cc05518b

Shieh Y. A., Yang S. J., Wei M. F., Shieh M. J. (2010): Aptamer-based tumortargeted drug delivery for photodynamic therapy. ACS Nano 4, 1433-1442 http://dx.doi.org/10.1021/nn901374b

Shim J. W., Tan Q., Gu L.Q. (2009): Single-molecule detection of folding and unfolding of the G-quadruplex aptamer in a nanopore nanocavity. Nucleic Acids Res. 37, 972-982 http://dx.doi.org/10.1093/nar/gkn968

Shum K. T., Tanner J. A. (2008): Differential inhibitory activities and stabilisation of DNA aptamers against the SARS coronavirus helicase. Chembiochem 9, 3037-3045 http://dx.doi.org/10.1002/cbic.200800491

Shum K. T., Lui E. L., Wong S. C., Yeung, P., Sam, L., Wang, Y., Watt, R. M., Tanner, J. A. (2011a): Aptamer-mediated inhibition of Mycobacterium tuberculosis polyphosphate kinase 2. Biochemistry 50, 3261-3271 http://dx.doi.org/10.1021/bi2001455

Shum K. T., Chan C., Leung C. M., Tanner J. A. (2011b): Identification of a DNA aptamer that inhibits sclerostin's antagonistic effect on Wnt signalling. Biochem. J. 434, 493-501 http://dx.doi.org/10.1042/BJ20101096

Skogen M, Roth J., Yerkes S., Parekh-Olmedo H., Kmiec E. (2006): Short G-rich oligonucleotides as a potential therapeutic for Huntington's Disease. BMC Neuroscience 7, 65-80 http://dx.doi.org/10.1186/1471-2202-7-65

Smirnov I., Shafer R. H. (2000): Lead is unusually effective in sequence-specific folding of DNA. J. Mol. Biol. 296, 1-5 http://dx.doi.org/10.1006/jmbi.1999.3441

Šnejdarková M., Svobodová L., Polohová V., Hianik T. (2008): The study of surface properties of an IgE-sensitive aptasensor using an acoustic method. Anal. Bioanal. Chem. 390, 1087-1091 http://dx.doi.org/10.1007/s00216-007-1749-2

So H. M., K. Won, Kim Y. H., Kim B. K., Ryu B. H., Na P. S., Kim H., Lee J. O. (2005): Single-walled carbon nanotube biosensors using aptamers as molecular recognition elements. J. Am. Chem. Soc. 127, 11906-11907 http://dx.doi.org/10.1021/ja053094r

Strehlitz B., Stoltenburg R. (2009): SELEX and its recent optimizations. In: Aptamers in Bioanalysis. (Ed. M. Mascini), pp. 31-59, J. Wiley \& Sons, Inc., Hoboken, New Jersey http://dx.doi.org/10.1002/9780470380772.ch2

Siddiqui-Jain A., Grand C. L., Bearss D. J., Hurley L. H. (2002): Direct evidence for a G-quadruplex in a promoter region and its targeting with a small molecule to repress c-myc transcription. Proc. Natl. Acad. Sci. U.S.A. 99, 11593-11598 http://dx.doi.org/10.1073/pnas.182256799

Tasset M. D., Kubik F. M., Steiner W. (1997): Oligonucleotide inhibitors of human thrombin that bind distinct epitopes. J. Mol. Biol. 272, 688-698 
http://dx.doi.org/10.1006/jmbi.1997.1275

Tong X., Lan W., Zhang X., Wu H., Liu M., Cao C. (2011): Solution structure of all parallel G-quadruplex formed by the oncogene RET promoter sequence. Nucleic Acids Res. 39, 6753-6763 http://dx.doi.org/10.1093/nar/gkr233

Trajkovski M., Sket P., Plavec J. (2009): Cation localization and movement within DNA thrombin binding aptamer in solution. Org. Biomol. Chem. 7, 4677-4684 http://dx.doi.org/10.1039/b914783g

Trajkovski M., da Silva M. W., Plavec J. (2012): Unique structural features of interconverting monomeric and dimeric G-quadruplexes adopted by a sequence from the intron of the $\mathrm{N}$-myc gene. J. Am. Chem. Soc. 134, 4132-4141 http://dx.doi.org/10.1021/ja208483v

Tombelli S., Minunni M., Mascini M. (2005): Analytical applications of aptamers. Biosens. Bioelectron. 20, 2424-2434 http://dx.doi.org/10.1016/j.bios.2004.11.006

Tsiang M., Gibbs C. S., Griffin L. C., Dunn K. E., Leung L. K. (1995): Selection of suppressor mutation that restores affinity of an oligonucleotide inhibitor for thrombin using in vitro genetics. J. Biol. Chem. 270, 19370-19376 http://dx.doi.org/10.1074/jbc.270.33.19370

Tucker W. O., Shum K. T., Tanner J. A. (2012): G-quadruplex DNA aptamers and their ligands: structure, function and application. Current Pharmaceutical Design, 18, 2014-2026 http://dx.doi.org/10.2174/138161212799958477

Tuerk C., Gold L. (1990): Systematic evolution of ligands by exponential enrichment: RNA ligands to bacteriophage T4 DNA polymerase. Science $\mathbf{2 4 9}, 505-510$ http://dx.doi.org/10.1126/science.2200121

Ueyama H., Takagi M., Takenaka S. (2002): A novel potassium sensing in aqueous media with a synthetic oligonucleotide derivative. Fluorescence resonance energy transfer associated with Guanine quartet-potassium ion complex formation. J. Am. Chem. Soc. 124, 14286-14287 http://dx.doi.org/10.1021/ja026892f

Víglaský V., Bauer L., Tlučková K. (2010): Structural features of intramolecular G-quadruplexes derived from telomeric repeats. Biochemistry 49, 2110-2120 http://dx.doi.org/10.1021/bi902099u

Víglaský V., Tlučková K., Bauer L. (2011): The first derivative of a function of circular dichroism spectra: biophysical study of human telomeric G-quadruplex. Eur. Biophys. J. 40, 29-37 http://dx.doi.org/10.1007/s00249-010-0625-8

Virgilio A., Esposito V., Citarella G., Pepe A., Mayol L., Galeone A. (2012): The insertion of two 8-methyl-2'-deoxyguanosine residues in tetramolecular quadruplex structures: trying to orientate the strands. Nucleic Acids Res. 40, 461-475 http://dx.doi.org/10.1093/nar/gkr670

Wallimann P., Kennedy R. J., Miller J. S., Shalongo W., Kemp D. S. (2003): Dual wavelength parametric test of two-state models for circular dichroism spectra of helical polypeptides: anomalous dichroic properties of alanine-rich peptides. J. Am. Chem. Soc. 125, 1203-1220 http://dx.doi.org/10.1021/ja0275360

Wang Y., Patel D. J. (1993): Solution structure of the human telomeric repeat d[AG3(T2AG3)3] G-tetraplex. Structure 1, 263-282 http://dx.doi.org/10.1016/0969-2126(93)90015-9

Wang K. Y., McCurdy S., Shea R. G., Swaminathan S., Bolton P. H. (1993): A DNA aptamer which binds to and inhibits thrombin exhibits a new structural motif for DNA. Biochemistry 32, 1899-1904 http://dx.doi.org/10.1021/bi00059a003

Wang K. Y., Gerena L., Swaminathan S., Bolton P. H. (1995): Determination of the number and location of the manganese binding sites of DNA quadruplexes in solution by EPR and NMR. Nucleic Acids Res. 23, 844-848 http://dx.doi.org/10.1093/nar/23.5.844

Weiss J. N. (1997): The Hill equation revisited: uses and misuses. FASEB J. 11, 835-841

Wyatt J. R., Vickers T. A., Roberson J. L., Buckheit R. W. Jr., Klimkait T., DeBaets E., Davis P. W., Rayner B., Imbach J. L., Ecker D. J. (1994): Combinatorially selected guanosine-quartet structure is a potent inhibitor of human immunodeficiency virus envelope-mediated cell fusion. Proc. Natl. Acad. Sci. U.S.A. 91, 1356-1360 http://dx.doi.org/10.1073/pnas.91.4.1356

Xiao Y., Lubin A. A., Heeger A. J., Plaxco K. W. (2005a): Labelfree electronic detection of thrombin in blood serum by using an aptamer-based sensor Angew. Chem. Int. Ed. Engl. 44, 5456-5459 http://dx.doi.org/10.1002/anie.200500989

Xiao Y., Piorek P. D., Plaxco K. W., Heeger A. J. (2005b): A reagentless signal-on architecture for electron, aptamer-based sensors via target-induced strand displacement J. Am. Chem. Soc. 127, 17990-17991 http://dx.doi.org/10.1021/ja056555h

Xu Y., Yang L., Ye X. Y., He P. A., Fang Y. Z. (2006): An aptamerbased protein biosensor by detecting the amplified impedance signal. Electroanalysis 18, 1449-1456 http://dx.doi.org/10.1002/elan.200603566

Yoshida W., Mochizuki E., Takase M., Hasegawa H., Morita Y., Yamazaki H., Sode K., Ikebukuro K. (2009): Selection of DNA aptamers against insulin and construction of an aptameric enzyme subunit for insulin sensing. Biosens. Bioelectron. 24, $1116-1120$ http://dx.doi.org/10.1016/j.bios.2008.06.016

Zahler A. M., Williamson J. R., Cech T. R., Prescott D. M. (1991): Inhibition of telomerase by G-quartet DNA structures. Nature 350, 718-720 http://dx.doi.org/10.1038/350718a0

Zaitseva M., Kaluzhny D., Shchyolkina A., Borisova O., Smirnov I., Pozmogova G. (2010): Conformation and thermostability of oligonucleotide d(GGTTGGTGTGGTTGG) containing thiophosphoryl internucleotide bonds at different positions. Biophys. Chem. 146, 1-6 http://dx.doi.org/10.1016/j.bpc.2009.09.011

Zhu Q., Jing N. (2007): Computational study on mechanism of G-quartet oligonucleotide T40214 selectively targeting Stat3. J. Comput. Aided Mol. Des. 21, 641-648 http://dx.doi.org/10.1007/s10822-007-9147-6

Received: August 31, 2012

Final version accepted: November 5, 2012 